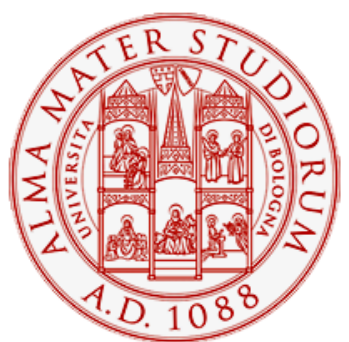

Alma Mater Studiorum - Università di Bologna DEPARTMENT OF ECONOMICS

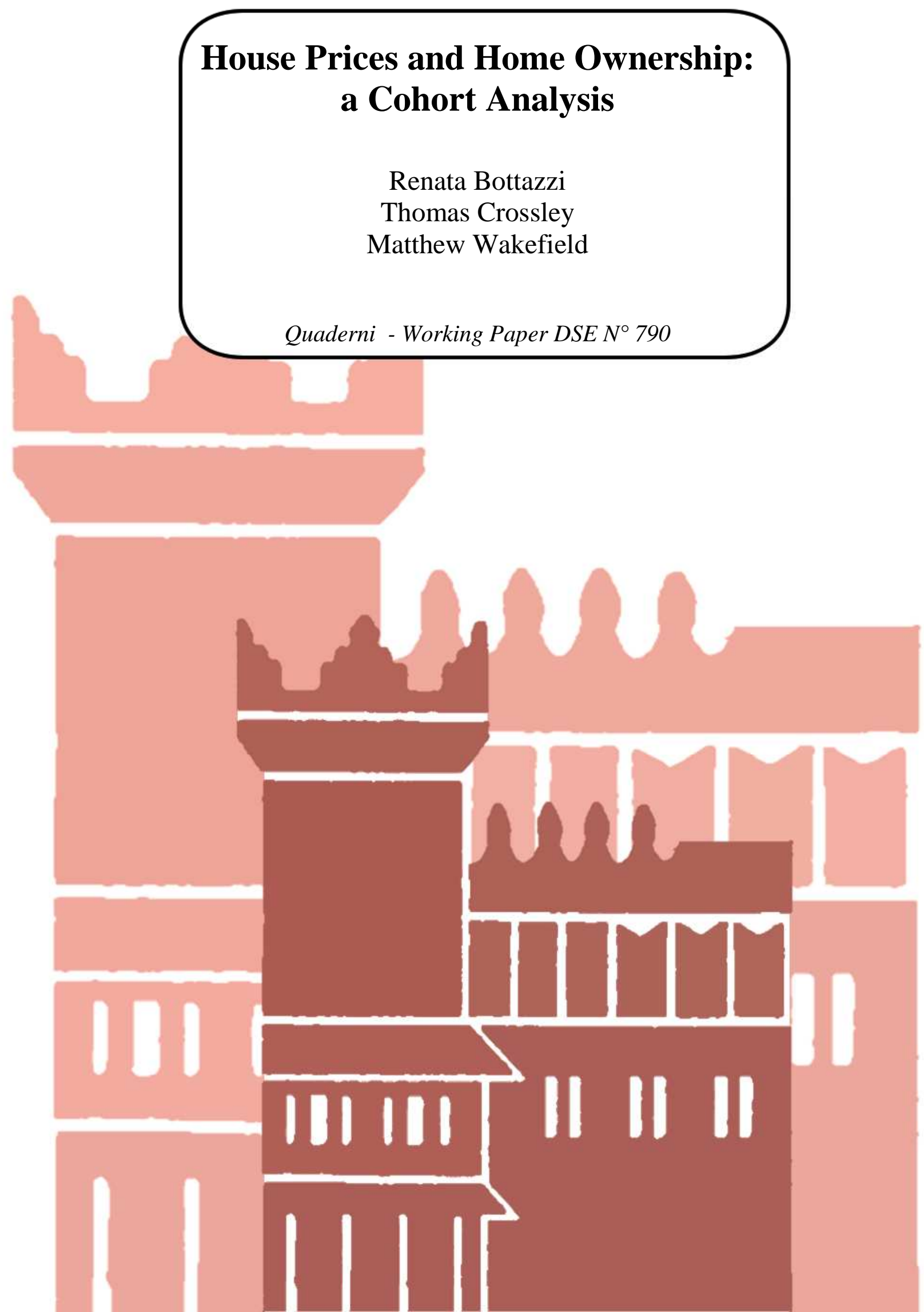




\title{
House Prices and Home Ownership: a Cohort Analysis
}

\author{
Renata Bottazzi, \\ University of Bologna, Institute for Fiscal Studies and CHILD \\ Thomas Crossley, \\ University of Cambridge and Institute for Fiscal Studies, London \\ Matthew Wakefield \\ University of Bologna and Institute for Fiscal Studies
}

February $2011^{1}$

\begin{abstract}
England has very volatile house prices. We use pseudo-panel data spanning multiple house-price cycles over nearly forty years, to assess the extent to which house prices affect access to homeownership by age thirty, and whether differences in ownership rates persist. We find that ownership rates at age thirty have varied substantially, with this variation significantly related to prices. Measurement error problems - attenuation bias and other biases - complicate an analysis of the persistence of these differences in ownership. We use two methods - including one that develops the ideas of Deaton (1985) - to deal with this and find robust evidence that cohorts with low ownership rates at thirty close about $80 \%$ of the ownership gap by age forty.
\end{abstract}

JEL Codes: R21, R31

Keywords: homeownership, pseudo-panel data, measurement error.

\footnotetext{
${ }^{1}$ Author order is alphabetical. This research has evolved from earlier work funded through the National Housing and Planning Advice Unit (NHPAU) Research Innovation Fund (Bottazzi et al., 2010). Bottazzi and Wakefield also acknowledge financial support from MIUR- FIRB 2008, project RBFR089QQC-003-J31J10000060001. We thank Carl Emmerson, Cormac O'Dea and seminar participants at the University of Bologna and at the Royal Economic Society Annual Conference 2011 for helpful comments. All errors are our own.
} 


\section{Introduction}

The birth cohort born in 1967 turned twenty-two in 1989. Some were graduating from university, while others had been in the labour market a few years. Most aspired to starting families and owning their own homes. In the United Kingdom, these twenty-two year olds faced a housing market in which average prices had been rising for seven years, and had risen $70 \%$ in real terms in the last four years. The ratio of average house prices to average earnings was 5.5. By contrast, when the cohort of 1975 turned twenty-two in 1997, house prices were more than $20 \%$ lower than in 1989 . Incomes had been catching up with prices, so that the house price to earnings ratio was 4 . In short, this cohort faced a very different housing market than the cohort that turned twenty-two eight years earlier. ${ }^{2}$ Do these differences matter?

These differences may matter both in the short run and in the long run. In the short run, cohorts faced with difficult housing market conditions may, on average, be delayed in 'getting on the property ladder.' Perhaps even more seriously, these differences may also matter for the longer run home-ownership rates of a cohort. Some members of a cohort that is delayed in its initial ownership transitions may find that they are never able to make the transition to owning their own home, and the ownership rate of the cohort may never 'catch up' to that of cohorts that faced more favourable initial conditions.

Recent theoretical modeling (Bottazzi, Low and Wakefield, 2007) suggests that housing market conditions early in a cohort's housing career matter in the short run, but not in the long run. Simulations indicate that disadvantaged cohorts catch up, so that they have comparable home ownership rates as they approach their fifties. However, these simulation results are sensitive to modelling choices, and so an empirical assessment of these questions remains important.

In this paper we provide such an empirical assessment. We use the repeated cross sections of the Family Expenditure Survey/Expenditure and Food Survey (FES/EFS) from 1969 to 2007 to answer two questions. ${ }^{3}$ First, as each birth cohort reaches adulthood how are their transitions to home ownership affected by market conditions? Specifically, if we compare two cohorts, one that faced a property boom in their twenty's and one facing a

\footnotetext{
${ }^{2}$ Sources: Department for Communities and Local Government (house prices) and ONS (Average Earnings).

${ }^{3}$ The name of this survey changed in 2001, although the content and design largely continued, so that it is possible to construct a consistent series.
} 
property slump, how different are their ownership at age twenty-five or thirty? Second, how persistent are the resulting differences? That is, do the home ownership rates of these two cohorts converge at older ages?

Our analysis employs cohort or "pseudo-panel" methods. The FES/EFS is not a true panel, in that individuals (or individual households) are not followed over time. However, because the FES/EFS provides us with a representative sample of the population in any survey year, it also gives us a representative sample of each birth cohort in any survey year. Thus we use the repeated cross-sections of the FES/EFS to track birth cohorts over time.

A brief preview of our results is as follows. Over the past forty years there has been considerable cross-cohort variation in the rate at which different birth cohorts' transition to home ownership. Ownership rates at thirty have ranged from around fifty percent to approximately seventy percent. This variation is related to house price developments over time, although that relationship seems stronger before 1990 than since. Overall, our results suggest that when a birth cohort faces house prices that are one standard deviation (or 17 percentage points) above trend in early adulthood, then the home-ownership rate of that birth cohort at age thirty is approximately 1.5 percentage points lower. Third, there is strong negative correlation between cohort ownership rates at age thirty and subsequent growth in ownership: cohorts that have low ownership at thirty appear to have fast growth in home ownership subsequently. Historically, cohorts with low home-ownership rates at thirty have closed about $80 \%$ of the "ownership-gap" by the time they reach age forty.

The rest of the paper is organized as follows. Section 2 elaborates on the historical context for our study, and describes the data and methods we employ (further detail on our data and methods is provided in a Technical Appendix.) Section 3 then analyses ownership at thirty and how this relates to house prices, and Section 4 considers the question of persistence. Section 5 concludes.

\section{Context, Data, and Methods}

\subsection{Context}

This study concerns the rate at which households have been able to get onto to the housing ladder during the last forty years. Housing market conditions, most notably house prices, have affected the affordability of home ownership during this period. Additionally, trends in access to finance and public policy reforms have affected the accessibility of home purchase. In this subsection we describe trends in average house prices, and in credit 
conditions, and also outline an important public policy programme that has affected homeownership rates (at different ages) in the years of the study. These trends and changes are factors that we will exploit, or need to take account of, in the analysis of the later sections of the paper.

Over the last 35 years, England has experienced three house price booms and two periods of significant house price decline. This can be seen in Figure 2.1.1, which shows a quarterly measure of the (mix-adjusted) average house price for England. Over the whole period 1969-2009, average real house prices in England increased by a multiple of almost four. As mentioned, this did not happen through a continuous upward trend. House price booms are seen in the early and middle 1970s, in the second half of the 1980s (during which period average real house prices rose by over $60 \%$ in four years), and in the period between 1995 and the early 2000s. Real terms house price falls were experienced between 1974 and 1977 (a period which was not followed by sustained price growth until after 1985), in the first half of the 1990s (during which period average real prices fell by almost forty percent), and between 2007 and 2009.

\section{[Figure 2.1.1 about here]}

Changes in house prices are not the only factor that have changed and will have affected the ability of households to get on and climb the property ladder during the last four decades. This is also a period during which substantial changes in credit markets took place. In addition, some public policy changes have been important.

Regarding credit conditions, the 1980s was a period of substantial credit market liberalization. Figure 2.1.2 shows the average ratio of mortgage advance to price in the U.K. during the period 1969-2008. Series for all agreed mortgage loans, and for first-time buyers only, are shown. The series show a jump up in the ratio (a fall in average down-payments) in the first two or three years of the 1980s, at the end of a period in which this ratio oscillated up and down. There is then a levelling out (or if anything a continued steady increase) in the advance to price ratio until around the middle of the 1990s, with some fall after that time. The sustained increase of the early 1980s might be thought of as an indicator of the relaxation of credit conditions, although care must be taken in interpretation as this measure will reflect the amount that lenders are prepared to lend to a given individual, the types of individuals that they lend to, and the amounts that individuals are prepared to borrow.

\section{[Figure 2.1.2 about here]}

As is clear from the thorough work of Fernandez-Corrugedo and Muellbauer (2006), detailed modelling work is needed to accurately quantify credit conditions. However, even in 
their exercises, the perceived trend through the 1980s is still evident. Describing their two measures of consumer credit conditions between 1975 and 2005, those authors write that "[b]oth indices increase in the 1980s, peaking towards the end of the decade. They fall partway back in the early 1990s, before increasing again towards the end of the sample" (ibid, p.4). A close look at their indices shows that the increase during the 1980s was particularly rapid during the first three years of that decade.

At the same time as the financial liberalization was taking hold, a major policy reform was also affecting the English housing market. This was the "right to buy" scheme which allowed council tenants (i.e. those renting social housing) the right to buy their properties at prices that were discounted compared to market values, with discounts depending on the length of tenancy. This became national policy ${ }^{4}$ with the passing of the Housing Act of (October) 1980, and resulted in a transfer of households from the social renting sector into owner-occupation. Figure 2.1.3 shows official statistics for the number of right to buy sales of local authority properties in England for each (financial) year from 1980/81. ${ }^{5}$ We see that there were particularly big spikes in such house sales at either end of the 1980s, with a smaller peak in the early 2000s; by 2008/09 almost 1.8 million local authority properties had been sold.

\section{[Figure 2.1.3 about here]}

\subsection{Data}

This study concerns the last three and a half decades in England. Panel data that track the same individuals over this entire period do not exist. The British Household Panel Study, for example, has excellent data on housing arrangements, but begins in 1991. Thus, only fifteen birth cohorts can be observed at any age, and only one house-price boom can be studied. While much important housing research can be done with these data, such as about the decision to leave the parental home (Ermisch, 1999), it is of limited use for our purposes. Instead, we use the Family Expenditure Survey/Expenditure and Food Survey (FES/EFS) which is available since 1968 and therefore allows multiple comparisons between cohorts that experienced favourable and unfavourable housing market conditions in their late twenties.

\footnotetext{
${ }^{4}$ Some local schemes had existed in the 1970s.

${ }^{5}$ For the raw data, see chart 671 via http://www.communities.gov.uk/housing/housingresearch/housingstatistics/housingstatisticsby/socialhousingsal es/livetables/
} 
The FES/EFS is an annual cross section of around 7,000 households, who record a two-week diary of their spending and information about purchases of durables and/or expensive items in recent months prior to the interview. Importantly for our study, the survey provides information on the housing tenure of respondents, as well as on their income, education, and family structure. In all our calculations we use the appropriate survey weights. We supplement the FES/EFS data with data on house prices and on sales of local authority housing through the right to buy scheme. We use official Government national and (for house prices) regional data, provided through the Department for Communities and Local Government (DCLG). ${ }^{6}$ The data on right to buy sales are those underlying Figure 2.1.3 above, while further information on how the house price data are set up may be found in the Technical Appendix.

\subsection{Methods}

The FES/EFS allows us to study the housing careers of more than thirty birth cohorts through synthetic cohort analysis. The basic idea of synthetic cohort analysis is as follows. With repeated cross sections we cannot track individuals over time. However, in each survey year we get a representative sample from each birth cohort, and so by using successive cross sections, we can follow the average characteristics of a birth cohort through time. In particular, for any birth cohort, we can estimate its ownership rate in every survey year and hence at different ages. Myers $(1999,2001)$ has emphasized the importance of accounting for cohort effects in the analysis of housing careers, and the utility of cohort studies as an important alternative to cross-sectional and longitudinal approaches to exploring housing patterns. Unlike cross-sectional analysis, synthetic cohort analysis allows for the disentangling of life-cycle (age) patterns from generational (cohort) differences. At the same time, cohort analysis often offers a longer time span than does the available panel data (as is the case here); in addition, the use of repeated cross-sections to follow synthetic cohorts avoids the attrition and small sample problems that often limit panel data analyses.

With thirty-nine FES/EFS surveys available to us (1969-2007) we can potentially follow some cohorts for thirty-nine years. However, we largely focus on ages thirty to fifty.

Although the FES/EFS are household surveys, we believe the appropriate unit of analysis is the individual and in this study we follow cohorts of individuals. Although it takes some care, birth cohorts of individuals can be constructed from the FES/EFS. The concept of

\footnotetext{
${ }^{6}$ See: http://www.communities.gov.uk/housing/housingresearch/housingstatistics/
} 
a "household life-cycle" is commonplace in economic studies, but such an approach has several drawbacks. A household is a collection of individuals, each of whom may belong to different cohorts and, at any given time, may be at a different stage of the life-cycle.

Although the ambiguity of a "household life-cycle" is well recognized, this ambiguity is often ignored because of the potential complexity of discerning individual profiles of household members from household data.

Moreover, many transitions in housing arrangements are associated with household formation or dissolution or with changes in household composition. Recent NHPAU research on affordability has focussed on the issue of household formation (NHPAU, 2008). Myers (1990) explains this concern with following the housing careers of households: "[w]hereas most housing research begins with the behaviour of households, the logical prior concern in this type of research is with the formation of households from a population" (p. 14). Housing studies that followed housing choices of (cohorts of) couples would miss much of the important action.

Instead, in this study, we follow cohorts of individuals. We do this separately for birth cohorts of men and women. To generate individual birth cohorts from household data, we create individual observations whenever we see an individual of a certain age and gender in a household record. The FES/EFS contains information on household and individual characteristics thus allowing us to create detailed records from which to construct individual birth cohorts for adults of all ages. Hence we will be able to track changes in housing tenure alongside changes in family composition for both men and women.

When structuring the data into cohorts of individuals, some care is required with allocating home-ownership. We take ownership to be a shared state, so that if we see a couple living in a property that is owned (with a mortgage or outright) by either member of the couple, then our data records both members of the couple as being owner-occupiers. Thus when we consider counts of individuals, both of these individuals will be counted as owners. However, we do not necessarily allocate the same ownership status to all members of a household. In particular, we are careful about how we allocate ownership for young adults who are still living in the parental home. Such individuals will appear as observations in our dataset, which includes all adults. However, even if the data record that the parents own their home, our analysis does not treat the children as home-owners. Recording ownership state in this way ensures that there is not an apparent fall in ownership in the early and middle twenties as individuals move out of home (often into the rental sector), followed by an increase when the same individuals become (first-time) buyers. 
In our analysis, we sometimes interpret the increase in the home ownership rate for a given cohort as the proportion of that group that became home owners between one year and the next. That is, we interpret this change as the gross flow in to housing between one year and the next. However, the flow that we observe is actually the net flow. That is, it is the number moving into home-ownership, net of the number transiting in the other direction back in to the rental sector. This net flow provides a close approximation to the gross flow if the number of individuals buying houses is much larger than the number of individuals in the same group (of the same age) who move from being owners back into the rental sector.

We undertook some preliminary analysis of this issue using the BHPS. Because the BHPS is a true panel, both gross and net flows are observed directly. Fortunately, for individuals in the age ranges that we are considering, net flows approximate gross flows quite closely. Among individuals in their twenties, there are relatively few individuals transiting back into renting because relatively few already own. Around age thirty the proportion of owners that switch to renting is around $2 \%$, and this tends to decline with age throughout the working life (being around $1 \%$ at age forty). Thus, though home-owners are in the majority at these ages, the numbers switching back to rental remains very small. ${ }^{7}$ We can, therefore, treat the observed net flow to ownership, as a close approximation to the gross flow, and we do this throughout the paper.

The size of the FES/EFS dataset allows us to split our analyses by region. Regional analysis is of independent interest; moreover, splitting by region potentially provides additional variation in prices to exploit. However, synthetic cohort analysis rests on the assumption that the composition of the cohort being followed is fixed over time. This assumption might be undermined if migration flows between regions are sufficiently large. We have investigated this issue empirically and concluded that it is reasonable to follow cohorts defined by birth-year and region. Further details are provided in the Technical Appendix.

\section{Getting on the Housing Ladder: Home ownership at thirty}

We begin by calculating the home ownership rate of men and women aged twentynine to thirty-one for every year in the data. Figures 3.1.1 to 3.1.4 display our finding on home ownership rates for individuals of age thirty, across time. The first figure shows the ownership rate across all individuals of that age. The second figure considers men and

\footnotetext{
${ }^{7}$ Full details are available on request.
} 
women separately. The third figure compares the North, South and Midlands regions to all of England. The final figure compares those individuals living as a member of a couple to all individuals. For each of these figures, the ownership rates were calculated using survey weights so that resulting rates are representative of the population of interest. The ownership rates are displayed alongside the (log) real house price series for this period (the same price data that were displayed in Figure 2.1.1, but at an annual frequency). The house price series is in red and the house price boom that began in the mid 1990s is clear in the graphs. In each figure the ownership series are in green or blue. Note that because we are holding age constant, the x-axis measures both survey year and birth cohort: thirty year-olds in 1970 are from the 1940 birth cohort and so on.

Over the past forty years there has been considerable cross-cohort variation in the rate at which different birth cohorts' transit to home ownership. Figure 3.1.1 shows that ownership rates at thirty range from around 50 percent to approximately 70 percent.

\section{[Figure 3.1.1. about here]}

The data in Figure 3.1.1 do suggest a relationship such that high prices restrict ownership, particularly before 1990. The peaks and troughs in prices before the mid 1980s approximately correspond to troughs and peaks in the age-thirty ownership rate. It is also the case that the strong run up in the house price after 1995 is associated with a downward drift in age-thirty ownership (although this downward drift did begin before house prices began to climb). However, between 1980 and 1985 the noticeable feature of the data is a strong surge in the age-thirty ownership rate, from around fifty-five percent, past its previous peak of almost sixty percent, and up to almost seventy percent. While this increase seemed to reverse somewhat as house prices began to grow rapidly in 1986 and 1987, it is worth noting that the reverse began before prices reached their peak in the late 1980s, but, as already noted, turned to a secular decline even while prices were falling at the beginning of the 1990s. It is likely that pressures other than prices - such as the already noted credit liberalization, and the "right to buy" policy - were affecting ownership rates strongly at some points between 1980 and the early 1990s, and in the figure this swamps the effect of the price on affordability.

\section{[Figure 3.1.2 and 3.1.3 about here]}

Figure 3.1.2 shows that the patterns of ownership rates for men and women aged thirty are quite similar. Some of the swings up and down in the ownership rate during the first part of the period were more marked for women than men, but the downward trend since 1990 seems more marked among men than among women. 
Figure 3.1.3 repeats the analysis by region. It shows that broadly the same patterns are observed in the North (top-right panel), Midlands (bottom-left) and South (bottom-right) as in England overall (top-left). However, the variations in both ownership rates and house prices are more pronounced in the South than elsewhere, and recent decline in ownership rates at thirty is particularly precipitous in the south.

\title{
[Figure 3.1.4 about here. ]
}

The right-hand panel of Figure 3.1.4 shows the trends only for those individuals in couples. Unsurprisingly, individuals in couples are more likely to be owners than is a random individual drawn from the whole population of thirty year-olds. Moreover, the ownership rate among thirty year-olds in couples has also declined less rapidly after 1990 than the ownership rate among all thirty year-olds. The trends for those in couples need not be the same as those for all individuals as those in couples are only a subset of the population, and because the proportion of the population who are living as part of a couple has been falling over time. The contrast between the left- and right-hand panels of Figure 3.1.4 suggests that the secular decline in ownership at thirty which has occurred since the early 1990s is related to the changing fraction of thirty year-olds in couples. This is further explored in Figure 3.1.5.

\section{[Figure 3.1.5 about here]}

A simple accounting identity is that:

\author{
Ownership rate of 30 year-olds $=$ \\ Fraction in a couple $\quad x \quad$ ownership rate among coupled 30 year-olds \\ + Fraction single $\quad x \quad$ ownership rate among single 30 year olds
}

Figure 3.1.5 shows that the ownership rate among coupled thirty-year olds has changed little since 1990. The ownership rate of single thirty-year olds has fallen a bit more. Young coupled individuals have always had higher ownership rates than young singles, and the proportion of thirty-year olds in couples has been falling (from over eighty percent in the 1970s, to around two-thirds in the early 1990s.) This accounts for a substantial component of the fall in the overall ownership rate of thirty-year olds.

While this observation provides a mechanical explanation of how the recent decline in ownership at thirty has occurred, a causal inference should not be drawn. It could be, for example, that the decline in the fraction of thirty year-olds who are a member of couple has been driven by a declining affordability of home ownership. The direction of causation is unclear. 
To quantify the relationship between house prices and ownership at thirty observed in these Figures, we now turn to econometric analysis. The Probit model reported in Table 3.1.1 was estimated with all thirty year olds in our data. Table 3.1.2 reports estimates for the subset of years (1978 on) for which education was recorded. In both cases the dependent variable is whether or not the individual owns a property at age thirty. As always we make appropriate use of survey weights. Standard errors are clustered on the region-year level to appropriately reflect the structure of our data.

Both models contain a linear time trend. Because we control for a linear trend, the estimated effect of house prices reflects the effect of deviations in house prices from a linear trend.

The models also include two variables measuring the number of "right to buy" sales of local authority housing in England. These two variables are intended to capture the impact of right to buy on the number of properties up for sale in a particular year, and on the size of the stock of properties in the owner-occupied sector, and respectively measure the number of right to buy sales (in hundreds of thousands) in the (financial) year in which an individual is observed and the cumulative number of sales (again in hundreds of thousands) since the right to buy became a national scheme in late 1980. Given the years in which the right to buy has been an active policy, it is possible that our right to buy variables also pick up some effects of the financial market changes discussed in Section 2.1. ${ }^{8}$

The variable for right to buy sales this year is significant in both specifications and the variable recording the cumulative number of sales is significant in Table 3.1.2; the estimates relating to these variables suggest that ownership at thirty has tended to be higher in years with greater numbers of right to buy sales, and higher still in later years for which the cumulative number of right to buy sales is greater. Unsurprisingly, family income and family characteristics (couple and number of children) are also strongly and significantly associated with the home ownership decision.

The log real house price variable is also significant and has a negative sign, indicating that higher prices are associated with lower ownership rates among thirty year-olds. This finding accords with the idea that a higher price makes home-ownership less affordable for thirty year olds. In Table 3.1.1, the marginal effect on the price variable suggests that if the house price is one standard deviation - or 17 percentage points - above trend, then home-

\footnotetext{
${ }^{8}$ We experimented with also including a variable indicating that an observation is from 1981 or after, but when included alongside the right to buy variables, all three were not separately statistically significant. We chose to keep the more interpretable measures of the impact of the policy.
} 
ownership would be approximately 3.2 percentage points lower. The corresponding marginal effect in Table 3.1.2 is slightly smaller, suggesting an ownership rate at thirty approximately 1.9 percentage points lower for every standard deviation that prices are above trend.

We experimented with adding lags of the $(\log )$ house price to the models presented, to investigate whether price effects are stronger if prices have been persistently high as a cohort approaches thirty than if they become high only near age thirty. We did not find significant evidence of such "dynamic price effects": a single lag of anything between one and five years was not significant and did not much affect the coefficient on the current price, while a formal statistical test indicated that even adding all five lags together did not significantly improve the explanatory power of the model. We conclude that the log of the current price is a sufficient control for price effects.

The results (notably for the price effects) are quite robust. Similar results are obtained whether we use the survey weights or not, and whether we use data for Great Britain rather than for England alone. ${ }^{9}$ House price effects are slightly smaller in magnitude (less negative) if only national (as opposed to regional) house price variation is used. Omitting individual characteristics (couple and number of children) from the model makes the marginal house price effect a bit stronger, while adding a post-1980 dummy to the model reported in Table 3.1.1 produces a result for the house price variable that is very similar to that reported in Table 3.1.2. Estimating models of this kind separately for men and women reveals very little difference. If we split the sample by education groups, the lower educated seem to experience a stronger house price effect. ${ }^{10}$

\section{[Table 3.1.1. and 3.1.2 about here]}

To summarize: home ownership rates at age thirty vary substantial across birth cohorts and the data support the idea that unfavourable housing market conditions in early adulthood are associated with delays in the transition of birth cohorts into home ownership.

\section{Is There Ownership Rate Catch-up After Thirty?}

We now turn to the question of whether those cohorts that were less able to get onto the ladder by thirty, were nonetheless able to "catch-up" with other cohorts at older ages. Do early differences in the rate of transition to home-ownership persist into later life? This is a

\footnotetext{
${ }^{9}$ Full results are available on request.

${ }^{10}$ Full results are available on request.
} 
critical issue from a number of policy perspectives. For example, home-ownership is a strong predictor economic security in retirement.

\subsection{Graphical analysis}

Figure 4.1.1, in which we present home-ownership rates at different ages across years, provides a first look at this question. The dashed blue line is the ownership rate for thirty year-olds, the dashed red line is this rate for forty year-olds, and so on with the solid grey line being the ownership rate among individuals aged seventy.

We see that for each group there is a substantial increase in the proportion of owners during the period before 1990, a time trend that reflects the right to buy policy and credit market liberalization, among other things. After 1990, the home ownership rate for thirty year olds declines sharply, as we saw for the ownership rate of thirty year olds in the figures of Section 3. This is a contrast to the ownership rates for other age groups, which stayed roughly constant or even continued to increase slowly. This contrast already suggests some catch up: individuals who were thirty in 1990 did not own substantially more when they were forty than was the case for those who were thirty five years later. Thus the higher ownership of the former group at thirty was offset by later transitions into owning for their successor cohort.

Tables 4.1.1 and 4.1.2 summarize the variation in ownership rates across cohorts, at different ages. Table 4.1.1 summarizes ownership rates at thirty and forty for those birth cohorts that we observe at both thirty and forty. Table 4.1.2 does the same for ownership rates at thirty and fifty for the smaller set of cohorts that we observe at both those ages (see also Table A.1 in the Technical Appendix). These Tables indicate that there is less dispersion in ownership rates across birth cohorts at older ages than at younger ages. This is again indicative of "catch-up".

\section{[Figure 4.1.1 about here]}

To look more directly at catch-up, in Figures 4.1.2 and 4.1.3, we plot increase in ownership between age thirty and age forty (in 4.1.2) and between age thirty and age fifty (in 4.1.3) against ownership at age thirty. In these figures, each point represents a birth-cohort (and the points are labeled by the birth year of the cohort). In each figure there are four panels. The top-left panel displays the relationship for cohorts defined by birth-year only (that is, for all of England). The remaining three panels repeat the analysis separately for each of three regions: North (top-right), Midlands (bottom-left) and South (bottom-right).

\section{[Tables 4.1.1 and 4.1.2 about here]}


Catch-up implies a negative relationship: lower ownership at thirty must be associated with a greater subsequent increase and higher ownership at thirty with less subsequent increase. This is exactly what we see in Figure 4.1.2 (catch-up by forty) and Figure 4.1.3 (catch-up by fifty). The same pattern is observed at the national level and in each region. For example, in the top left panel of Figure 4.1.2, we see that the 1940 birth cohort (thirty in 1970) has a low home ownership rate at age thirty of $47 \%$ (see also Table A.1 in the Appendix) but experiences a substantial increase in home ownership - of 16 percentage points - between ages thirty and forty. In contrast, the 1954 birth cohort (thirty in 1984) has a much higher home ownership rate at age thirty of $71 \%$ but experiences very little increase in home ownership - just 2 percentage points - between ages thirty and forty.

[Figures 4.12 and 4.13 about here]

However, there is a problem with these figures. We know that ownership at thirty is measured with error. For each cohort, it is an estimate, based on the representative sample of that birth cohort found in the appropriate year of the FES/EFS. These estimates are naturally subject to sampling error, and this sampling error is effectively a kind of measurement error (Deaton, 1985). The ownership rate at thirty will be slightly over-estimated for some cohorts, and slightly under estimated for others. This measurement error may affect the figures in two ways.

First, ownership at thirty appears on the horizontal axis in each figure. Measurement error in the horizontal variable creates attenuation bias and makes the relationship appear flatter than it actually is; in the case of a negative relationship like that documents in Figures 4.1.2 and Figure 4.1.3, this means the slope is less negative than it should be, understating the true degree of catch-up.

Second, ownership at thirty is also used to construct the variable (change in ownership) on the vertical axis, which it enters negatively. Ownership rates at forty will be subject to sampling error as well, but because these are based (for each cohort) on an independent sample, the sample errors in ownership at forty will be unrelated to sampling errors in ownership at thirty. The way ownership at thirty features on both axes means that cohorts that have positive measurement errors in ownership at thirty will appear to have smaller subsequent increases in ownership. Measurement error in ownership at thirty therefore creates a spurious negative correlation between change in ownership (on the vertical axis) and ownership at thirty (on the horizontal axis.) This makes the relationship appear more negative than it actually is, overstating the true degree of catch-up. (These arguments are formalized in Appendix, Section c). 
These two effects operate in opposite directions so that the direction of net bias in unclear. In the next section, we employ two methods that allow us to circumvent these measurement problems and quantify the degree of catch-up.

\subsection{Regression analysis}

To quantify the catch-up suggested by the figures in the previous subsection, we regress the change in the ownership rate between thirty and forty, on the ownership rate at age thirty. Catch-up implies a negative coefficient on the initial condition (ownership at age thirty). If subsequent increases in home ownership are unrelated to ownership rates at thirty, then the coefficient on the latter should be zero. Complete catch-up corresponds to a coefficient of minus one. In this case of complete catch-up, cohort ownership rates at forty are not predicted by ownership at thirty.

We focus on catch-up between thirty and forty because this maximizes the number of birth-cohort observations we can use in estimation. (In a given set of survey years, not all birth-cohorts are seen at all ages, and more cohorts are observed at both ages thirty and forty than at ages thirty and fifty.) Note that, unlike the econometric model reported in Section 3, which was estimated on individual level data, the model here is estimated on cohort -level data (each observation is a birth cohort of individuals). It is infeasible to estimate this growth model on the pooled individual data because each individual is observed only once: it is only the birth cohort that is observed at more than one age. We use a linear model this time because our dependent variable is not dichotomous but rather is measured in percentage points. The results are presented in Table 4.2.1.

We first estimate this model by ordinary least squares and the results of this estimation procedure are presented in column (1). In this regression the ownership rate at thirty is significant and negative - as we would expect given the figures in the previous subsection. The coefficient of -0.871 suggests that around $87 \%$ of the variation in birth cohort home-ownership rates at age thirty is made up by age forty, and we cannot reject a coefficient of -1 (i.e. complete catch up). In column (2) we add to this model a time trend, a dummy for reaching thirty in or after 1981, and the fraction of the cohort that were in a couple at thirty. This results in a slightly larger estimate of the extent of catch-up of about $93 \%$.

However, these ordinary least squares estimates suffer from exactly the same problem as was described for Figures 4.1.2 and 4.1.3 in the previous subsection. Biases arising from measurement error in ownership at age thirty may lead to either over- or underestimates of the degree of catch-up. 
There are two possible approaches to overcoming these problems. The first approach is to re-estimate our regression model by two-stage least squares (2SLS), using the ownership rate at age twenty-nine as an instrument for our mis-measured independent variable, ownership at thirty. The ownership rate of a birth-cohort at age twenty-nine is very closely related to its ownership rate at thirty. The ownership rate at twenty-nine is measured with error, for the same reasons that the ownership rate at thirty is. However, because for each cohort the ownership rates at twenty-nine and thirty are based on different survey years (and hence independent samples), the measurement (or sampling) error in the ownership rate at twenty-nine should be unrelated to the measurement (or sampling) error in the ownership rate at thirty (and forty). Thus the ownership rate at age twenty-nine is an ideal instrumental variable in this context.

The results of this exercise are presented in columns (3) and (4) of Table 4.2.1. Relative to the OLS estimates, the point estimates of the catch-up coefficient are somewhat diminished in magnitude. For example, for the specification with no additional controls, the coefficient goes from -0.871 to -0.835 (so that estimated degree of catch-up goes from $87 \%$ to $84 \%$.) This is consistent with the OLS estimate being slightly downward-biased by measurement error. The 2SLS estimate still suggests substantial catch-up, although the coefficient is now much less precisely estimated.

The second approach to overcome the measurement error bias is based on the observation that the coefficient of interest can be corrected for the measurement error if an estimate of the degree of measurement error is available. In the case of pseudo-panel analysis, as observed by Deaton (1985), such an estimate is available because the measurement error is just sampling error in the estimation of a mean. Expressions for corrected estimators provided in that paper cannot be applied directly to our catch-up regressions and full details of the correction we apply are given in Appendix, Section c. Essentially, consistent estimates of the variance of the measurement error are computed from micro-data and then used to remove biases from an OLS-type estimator.

The results from this second approach are presented in columns (5) and (6) of Table 4.2.1 along with bootstrapped confidence intervals. The coefficients on ownership at thirty are now -0.798 and -0.774 , respectively, for the specifications without and with additional controls. These results are very much in line with the instrumental variables estimates. Both suggest a relatively small net effect of biases due to measurement error on the OLS estimate. 
Taken together, these estimates, using two different methods to correct for possible measurement error bias suggest a very robust result. There is substantial catch-up, and cohorts with low home-ownership rates at thirty have closed about $80 \%$ of the "ownershipgap" by the time they reach age forty.

\subsection{Further tests}

While the analysis supports the hypothesis of "catch-up" in home-ownership rates, it does not rule out the possibility that ability to get on to the housing ladder by age thirty persistently affects the amount of housing assets that cohorts are ultimately able to purchase. To investigate this we used information on the number of rooms in accommodation as a proxy for the amount of housing owned. After controlling for a general upward drift over time in the recorded number of rooms in accommodation in our FES/EFS data, we were unable to find any significant evidence of a relationship between the level of ownership at age thirty and the number of rooms owned, on average, by age forty (regression results available on request). To the extent that this failure to find evidence reflects that there is little or no relationship between the two variables (rather than that cohort data do not provide enough observations to investigate this relationship in detail), this result supports the idea that cohorts who are less able to get onto the housing ladder by thirty are not subsequently scarred in terms of the amount of housing assets that they are able to buy. Thus we can think of these results as additional, albeit weak, evidence in favour of the "catch-up" hypothesis. ${ }^{11}$

There still remain other aspects of housing careers that we have not analysed. Ability to get on to the housing ladder by thirty may affect the age by which households are able to become outright owners. The EFS/FES surveys do also contain information on this. However, preliminary analysis of the data indicated that there is little point in looking at outright ownership before about age sixty. There are only nine cohorts that we observe both at thirty and at sixty. Any analysis of the effect of housing market conditions in early adulthood on outcomes at age sixty would therefore be based on this very small number of birth-year cohorts and, importantly, would not be based on multiple housing booms and busts. Thus a credible examination of such issues may require different data or methods.

\section{Conclusions}

\footnotetext{
${ }^{11}$ Full details available on request.
} 
Due to the fact that England experiences significant house price volatility, with booms and busts, different birth cohorts have experienced very different housing market conditions in early adulthood. It is natural to ask whether these fluctuations have been associated with different home ownership outcomes for the birth cohorts that experienced them, and whether the differences, if present, persist into later life.

There are number of ways that one could address these questions. In this paper we have investigated these questions empirically, employing successive FES/EFS surveys over almost forty years, in conjunction with pseudo-panel methods. These data and methods allow us to track the ownership rates of different birth cohorts over a time period that captures three housing booms, and two housing busts.

We find that, over the past forty years, ownership rates at age thirty have varied substantially across birth cohorts. This variation is related to house prices, but the relationship may be stronger before 1990 than subsequently. These patterns are common to men and women, and to the different regions of England. They are more pronounced in the south than nationally. Overall, our results suggest that when a birth cohort faces house prices that are one standard deviation (or 17 percentage points) above trend in early adulthood, then the home-ownership rate of that birth cohort at age thirty is approximately 1.5 percentage points lower.

There has been a secular decline in ownership at age thirty from the early-1990s on. This is associated with a coincident decline in the fraction of thirty year olds in couple households. This correlation should be interpreted with care. Causality might run from household formation to housing demand, or from housing prices or supply to household formation, or both, or neither.

Those birth cohorts that were less likely to get onto the ladder by thirty were nonetheless subsequently able to "catch-up", to a large degree, with cohorts that experienced more favourable initial conditions. Measurement error means that the raw correlation between ownership at thirty and subsequent growth in ownership, may misstate the true degree of catch-up. Nevertheless, two different econometric methods which address that problem, and ancillary evidence, suggest that the apparent catch-up is real. Cohorts with low home-ownership rates at thirty have closed about $80 \%$ of the "ownership-gap" by the time they reach age forty.

As with any analysis, ours has limitations. An obvious limitation of the analysis in this paper is that it only documents the association of housing market conditions with the experiences of successive cohorts of young adults, and stops short of drawing causal 
inferences. While these associations are certainly suggestive of an effect of housing market conditions on outcomes, it is quite possible that there are important effects that run in the opposite direction - from the size and characteristics of different birth cohorts reaching young adulthood to housing market conditions. Disentangling these different effects is important, but beyond the scope of this paper..It is nevertheless important to document, as this paper does, the key facts on cohort home ownership as a basis for further empirical work and as targets for any structural modeling to match. 


\section{References}

Attanasio, O., A. Leicester and M. Wakefield (2008), "Using theory and simulation methods to understand the relationship between house prices and consumption growth in the UK", conference paper, prepared for the Royal Economic Society annual conference, http://www.ifs.org.uk/publications.php?publication_id=4211.

Banks, J., R. Blundell, Z. Oldfield and J. Smith, (2005). "House Price Volatility and Housing Ownership Over the Life-cycle.” Department of Economics, University College London, Discussion paper 04-09.

Bottazzi, R. (2004), "Labour market participation and mortgage-related borrowing constraints”, IFS Working Paper 04/09, Institute for Fiscal Studies, London.

Bottazzi, R., Crossley, T.F. and M. Wakefield (2010), "How do Housing Price Booms and Busts Affect Home Ownership for Different Birth Cohorts? National Housing and Planning Advice Unit Report.

Bottazzi, R., H. Low and M. Wakefield (2007), "Why do home owners work longer hours?", IFS Working Paper W07/10.

Chiuri, M.C. and T. Jappelli (2003), "Financial market imperfections and home ownership: A comparative study”, European Economic Review, 47(5), pp. 857-875.

Chiuri, M.C. and T. Jappelli (2010), "Do the elderly reduce housing equity? An international comparison”, Journal of Population Economics, 23(2), pp. 643-663.

Crossley, T.F. and Y. Ostrovsky (2003), 'A Synthetic Cohort Analysis of Canadian Housing Careers' SEDAP Research Paper \#107, McMaster University.

Deaton, A. (1985), 'Panel Data From a Time Series of Cross-Sections,' Journal of Econometrics, 1985, pp. 109-126.

Duncan, G. and Hill, M., (1985). "Conceptions of Longitudinal Households: Fertile or Futile?" Journal of Economic and Social Measurement, 13, pp. 361-375.

Ermisch, J. (1999), "Prices, parents and young people's household formation," Journal of Urban Economics, 45, pp.47-71.

Fernandez-Corugedo, E. and J. Muellbauer (2006), Consumer credit conditions in the United Kingdom, Bank of England Working Paper 314, (http://www.bankofengland.co.uk/publications/workingpapers/wp314.pdf)

Jappelli, T. (1999), “The Age-Wealth Profile and the Life-Cycle Hypothesis: A Cohort Analysis with Time Series of Cross-Sections of Italian Households," Review of Income and Wealth, 45(1), pp.57-75.

Kapteyn, A., R. Alessie and A. Lusardi (2005), "Explaining the wealth holdings of different cohorts: Productivity growth and Social Security”, European Economic Review 49 (2005) $1361-1391$

Myers, D., (1990). "Introduction: The Emerging Concept of Housing Demography," in Housing Demography: Linking Demographic Structure and Housing Markets (ed. D. Myers). The University of Wisconsin Press, Madison. 
Myers, D., (1999), "Cohort Longitudinal Estimation of Housing Careers," Housing Studies, 14(4), pp.473-490.

Myers, D., (2001), "Reply to Frans Dieleman: Better Use of Cross-sectional Data," Housing Studies, 16(1), p.123.

NHPAU (2008), "Impact of worsening affordability on demand for social and affordable housing: tenure choice and household formation", NHPAU Research Findings, Number 2.-- 


\section{Technical Appendix}

This Technical Appendix provides further detail on our data and methods.

\section{a. House-price data}

Throughout this paper the house price data that we have used are based house price indices published by the Department for Communities and Local Government (DCLG), and freely available via http://www.communities.gov.uk/housing/housingresearch/housingstatistics/livetables/. The main indices that we use are published in table 590 from the above link in the section on the housing market and house prices, under the subheading house price index. The indices are mix adjusted, where the mix adjustment is to allow for the fact that the composition of house types traded in the housing market changes from year to year (e.g. some years a higher proportion of large detached properties are traded, other years flat sales are more important). We use quarterly data that are available since quarter two of 1968. The data include separate series for the UK, for England, Scotland, Northern Ireland and Wales, and for English regions (nine "government office regions"). In the main we use the series for England, or the series for English regions, depending on which is appropriate to the analysis.

To convert from the price index into a price level, we use mix-adjusted prices for quarter 1 (February) of 2002, which are also published by and freely available from DCLG.

To convert these nominal house prices in real prices we deflate using the all-item Retail Prices Index, and we deflate to December 2007 prices (2007 is the latest year in our FES data on ownership). The RPI data are published by the Office for National Statistics, and we have monthly data. To deflate the quarterly house price series we use the (mean) average of the RPI for the 3 months corresponding to each quarter.

Though the basis is the house price data is quarter two of 1968 to quarter one of 2009, not all the English regions have data for the full period due to changes in the drawing of regional boundaries. In particular the North-East, East (i.e East Anglia) and South East series are available from quarter two of 1992, while the North West series is available from quarter one of 1999. When exploiting regional data, we either drop region-years in which the house price is not available, or, for the figures plotting the house price and ownership in broad English regions, we construct the price series based on only a subset of the more narrow regions that are the constituent parts of our broader regions. 


\section{b. Pseudo-Panel Analysis: checking for group consistency}

As mentioned above, before we apply synthetic cohort analyses to regional samples, we need to conduct some checks on the data to make sure it is valid to do so.

The cohort methods hinge on cohort composition remaining constant over time. Random samples of fifty year-olds in 1980 and 60-years olds in 1990 are informative about the average experience of individuals in the 1930 birth cohort if the set of people in the population with that characteristic (born in 1930) is fairly constant between 1980 and 1990. If that is not the case then changes in the home ownership rate between 1980 and 1990 will confound changes in the home ownership rate among the individuals that the 1980 sample was drawn from with changes in the composition of the cohort.

At a national level, the main threats to the validity of this assumption are (i) immigration, (ii) emigration, and (iii) differential mortality. For example, suppose that the 1930 birth-cohort experiences some mortality between 1980 and 1990 and that this mortality is concentrated in amongst those with lower socioeconomic status and wealth. As these people are less likely to own homes this can lead to a rise in the home ownership rate of the cohort even though there is no change in the home ownership probability of any given individual in the cohort. As we are ultimately interested in the life-course experience of individuals, we would consider this a spurious selection (or compositional) effect. Similar effects arise if, for example, immigrants who join a cohort as it ages have lower (or higher) home ownership rates than the native born.

Turning to regional analysis, we face two main difficulties. First, if we look at smaller regions then the available sample for any given birth cohort in any given survey year can be quite small. These small cell sizes then lead to considerable sampling variation in the home ownership rate of a given birth-cohort, at a given age, in a given region. The resulting age paths of home ownership are therefore be potentially quite noisy, with meaningless year-onyear variations.

The second problem is that threats to the validity of the constant birth cohort composition assumption are potentially more severe at the regional level. This is because inter-regional migration might be greater than international migration.

There is a way to check these issues internally in the data. The idea is to use the data to track across age a characteristic (or characteristics) of a birth-cohort (or birth/region cohort) that we believe should be constant. If cohort composition does change over time, we 
might expect this to be manifest in these age profiles. To implement this idea, we organized the data for England into three large regions (South, Midlands and North) and within each region, into 10-year birth cohorts. We then examine two features of each cohort as it ages: cohort size, and the fraction of individuals in the cohort who left full-time education at or after age 18. Changes in estimated cohort size would reflect mortality as well as migration into and out of the region. The fraction of individuals in the cohort who left full-time education at or after age 18 should of course be roughly constant after age 18 and if it changes as the cohort ages this would indicate either differential mortality or that higher (or lower) education individuals are being added (or subtracted) from the cohort by migration.

The results of this analysis are presented in Figures A.1 and A.2. As always we have been careful to use the survey weights in all calculations. Figure A.1 shows the estimated cohort size for a set of cohorts defined by region of residence (South, Midlands, North) and 10 year birth cohort (1930s, 1940s, 1950s, 1960s). Size is on the vertical axis and age on the horizontal axis. Vertical differences between cohort lines indicate "cohort effects." For example, particularly in the South, the 1960s birth cohort (in yellow) is significantly larger than the 1930s cohort (in blue). The line for each cohort traces out the age profile for that cohort. This figure shows some mild decline in estimated cohort size as each cohort ages, which probably reflects a combination of mortality and net emigration. There is some suggestion of an accelerated decline in cohort size past age 65 (which we see in our data only for the 1930s cohort) which might be consistent with accelerating mortality or emigration associated with retirement.

\section{[Figure A.1 and A.2 about here]}

The key point that we draw from Figure A.1, however, is that changes in estimated cohort size are quite modest (at least before age 65) and very similar across birth cohorts and regions. We would have been rather more concerned if Figure A.1 showed cohorts in one region growing while cohorts in other regions shrank, indicating substantial net migration between regions. This does not, however, appear to be the case.

Figure A.2 follows the same pattern but traces out the fraction of individuals in the cohort who left full-time education at or after age 18. The age profiles of the different cohorts are fairly noisy, and perhaps exhibit some small upward trend with age. The latter would be consistent with differential mortality (higher socioeconomic status individuals having greater life-expectancy) and/or some incidence of older individuals returning to school. The main point again is that the age effects do not appear to be dramatic, and do not appear to differ significantly across regions. 
It would certainly be possible to push this analysis further, for example by subjecting the age profiles apparent in these figures to formal statistical tests. But our conclusion from these figures is that analysis at the level of broad regions is feasible, and the constant composition assumption is no more dangerous at this level of region than at the level of England as a whole. On the other hand, the sampling variability in age profiles apparent especially in A.2 suggests to us that, due to small sample sizes, analysis at the level of more disaggregated regions would not be advisable.

\section{c. Correcting for Measurement Error in Cohort Data}

Section 4 gave results from a method for correcting pseudo-panel estimates for measurement error bias (that is due to sampling variation). The technical details of the correction are given here. Wherever we use these corrected estimators, confidence intervals are bootstrapped using 1000 replications.

In the presence of measurement error, OLS regression estimates are biased and the extent of the bias depends on the measurement error variance. An insight from Deaton (1985) is that, with pseudo-panel data, the measurement error variance ( $\sigma_{u}^{2}$ below) is just the sampling variability of the cohort-year cell mean, which can be estimated by standard methods. With an estimate of the variance of the measurement error in hand, it is possible to correct the OLS estimate. Since we cannot directly apply Deaton's corrected estimators in our "catch-up" regressions, we provide details of our corrected estimators here. In our case, the explanatory variable of interest $\left(x^{*}\right)$ is ownership at thirty, while the outcome of interest $\left(y^{*}\right.$ $\left.x^{*}\right)$ is the change in ownership between thirty and forty.

A characterisation of the biases due to measurement error in our "catch up" regressions and the derivation of the estimators are as follows.

For the univariate case, let $x^{*}$ and $y^{*}$ indicate true variables and let $x$ and $y$ be the variables we observe with errors $u$ and $v$, respectively (omitting year subscripts for $y, x$, and $\varepsilon)$ :

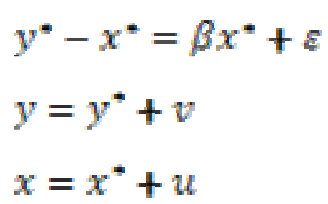

We make standard assumptions about the structure of the model and of measurement errors: 


$$
\begin{aligned}
& p \lim \frac{1}{n} \sum x^{*} \varepsilon=p \lim \frac{1}{n} \sum x^{*} u=p \lim \frac{1}{n} \sum x^{*} v=0 \\
& p \lim \frac{1}{n} \sum u \varepsilon=p \lim \frac{1}{n} \sum v \varepsilon=0
\end{aligned}
$$

We denote variances and covariances of true variables and measurement error as

$$
\begin{array}{ll}
p \lim \frac{1}{n} \sum x^{* 2}=\sigma_{x^{*}}^{2} & p \lim \frac{1}{n} \sum y^{*} x^{*}=\sigma_{y^{*} x^{*}} \\
p \lim \frac{1}{n} \sum u^{2}=\sigma_{u}^{z} & p \lim \frac{1}{n} \sum u v=\sigma_{u v}
\end{array}
$$

In our case $u$ and $v$ are sampling errors from different independent samples so from now on we assume $\sigma_{u v}=0$.

The OLS estimator based on observed variables is (with sums taken over years)

$$
\beta^{\text {OLS }}=\left(\sum x^{2}\right)^{-1} \sum(y-x) x
$$

(Note that throughout this Section and in our implementation of the estimator $x$ and $y$ variables are in deviations from means.)

This estimator is not consistent, having

$$
p \lim \beta^{O L S}=\frac{\beta \sigma_{x^{4}}^{2}-\sigma_{u}^{2}}{\sigma_{x^{2}}^{2}+\sigma_{u}^{2}}=\frac{\beta \sigma_{x^{4}}^{2}}{\sigma_{x^{4}}^{2}+\sigma_{u}^{2}}-\frac{\sigma_{u}^{2}}{\sigma_{x^{4}}^{2}+\sigma_{u}^{2}}
$$

This last expression characterises the effects of the measurement error. The first element in the last sum above is standard attenuation bias due to measurement error in the $x$ variable, and tends to make the estimator smaller in magnitude. The second element, will tend to bias the estimator towards -1 (as the variance in the true $x$ goes to zero).

We can correct the estimate using the following expression, which is the estimator used in Section 4 (column (5) of Table 4.2.1):

$$
\beta^{F L S}=\left(\sum \mathbb{Z}\left(x_{u}^{2}-s_{u}^{2}\right)\right)^{-1} \sum \mathbb{Z}\left((y-x) x+\rrbracket s_{u}^{2}\right)
$$

where $s_{u}^{\underline{Z}}$ is a consistent estimate of $\sigma_{u}^{\underline{Z}}$. In our case, this is the variance of the cohortyear sample mean of ownership at thirty, which can be estimated from the pooled micro-data underlying the pseudo panel. In doing this, we weight cohort-year cells to allow for differences in cell size. 
Maintaining notation as much as possible (vectors in bold and $t$ an index for year), the multivariate case is

$$
y_{t}^{*}-x_{1 t}^{*}=x_{t}^{* \beta}+\varepsilon_{i}
$$

with $x_{1}$ being the first element of the $x$ vector, which is ownership at thirty.

The assumptions on the structure of the measurement error are such that the limiting distribution of the variance-covariance matrix of measurement errors is

$$
\left(\begin{array}{cc}
\sigma_{v}^{z} & 0^{\prime} \\
0 & \Sigma_{u u}^{z}
\end{array}\right)
$$

with $\mathbf{0}$ in this matrix again following from having sampling errors associated with independent samples and $\Sigma_{u u}$ being the covariance matrix of the measurement error in the $x$ variables (in our case, two of the $x$ variables, the time trend and the dummy for year 1981 or after, are based on sample year and so measured without error).

In this case, OLS estimator based on observed variables is again inconsistent, with

$$
\begin{aligned}
& \text { plim } \beta^{O L S}=\left(\Sigma_{x^{*} x^{*}}+\Sigma_{u u}\right)^{-1}\left(\Sigma_{x^{*} x^{*}} \beta-\sigma_{u u_{1}}\right) \\
& \text { and } \sigma_{u u_{1}} \text { being the first column of } \Sigma_{u u s} \text {, that is, the variance and covariances }
\end{aligned}
$$

between the measurement errors in $x_{1}$ and in each $x$-variable.

The feasible consistent estimator used in Section 4 (column (6) of Table 4.2.1) is then

$$
\left(X^{\prime \prime} X-T s_{u u}\right)^{-2}\left(X^{\prime}\left(y-x_{1}\right)+T s_{u u_{1}}\right)
$$

with $X$ the $x$-variables stacked up by year and $T$ the number of years (28 in our data), $S_{u u}$ a consistent estimate of $\Sigma_{u u}$ and $\boldsymbol{s}_{u u_{1}}$ its first column. Again, these estimates come from the pooled micro-data.

\section{d. Further Descriptive Statistics}

This subsection provides further detail on the pseudo-panel data constructed from successive FES/EFS surveys.

[Tables A.1 and A.2 about here] 
Figure 2.1.1 Log real house prices in England, 1968 - 2009 (quarterly)

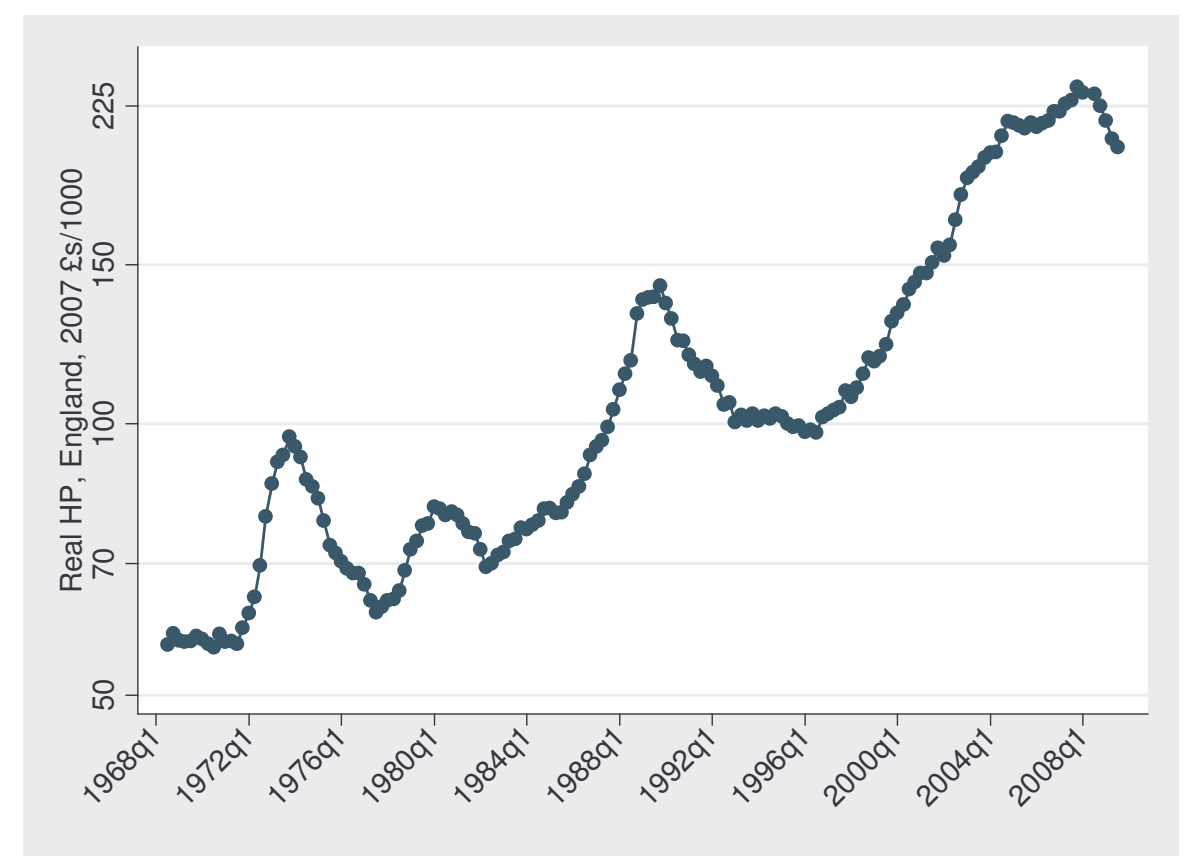

Notes: DCLG data for the mix-adjusted house price series (quarterly), deflated by the authors using the all item retail prices index. The final data point shown is 2009, Q1. More detail on the price data is available in the technical appendix to this paper. The vertical axis is labeled in (2007) pounds, although the axis is plotted on a logarithmic scale. A (very similar) U.K. version of the figure is available from the authors on request. 
Figure 2.1.2 Average mortgage advance to price ratios in the UK, 1969 - 2008

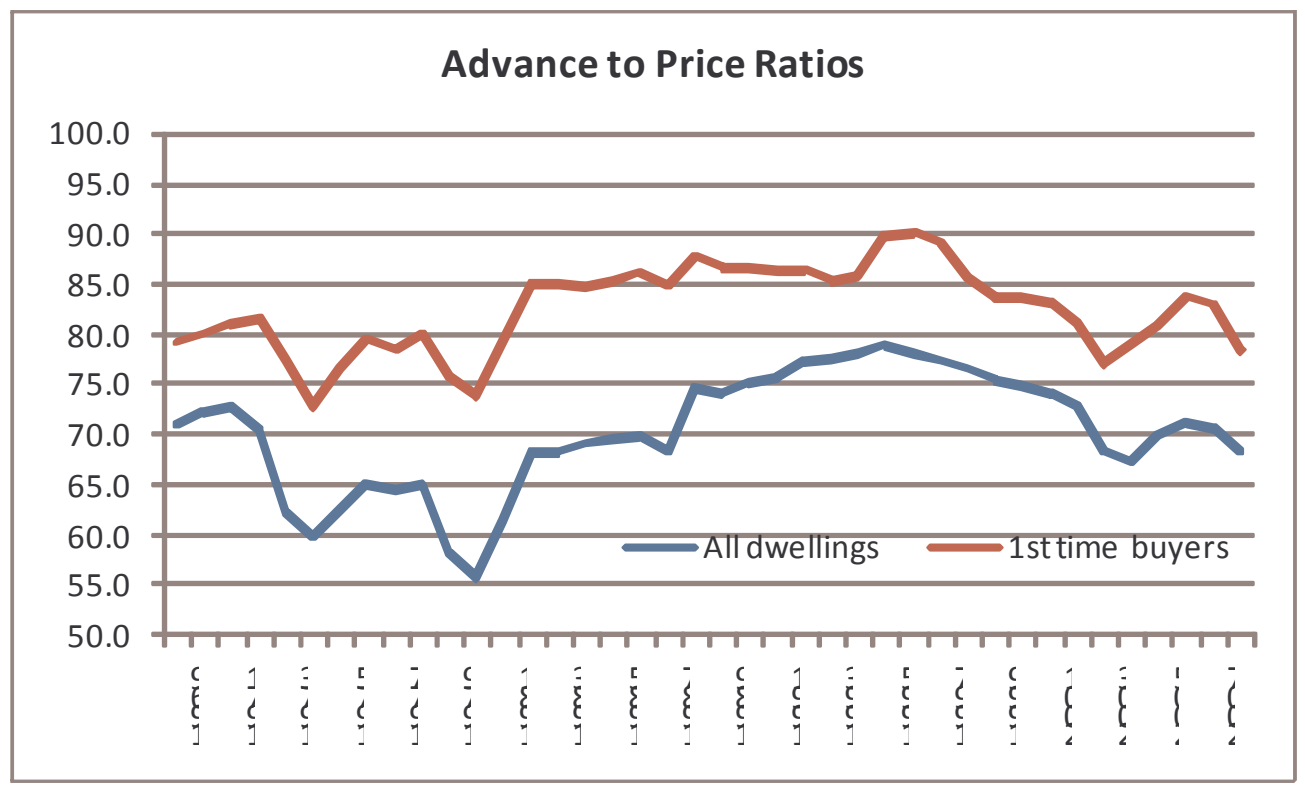

Notes: Data are available from DCLG

(http://www.communities.gov.uk/housing/housingresearch/housingstatistics/housingstatisticsby/housingmarket/livetables/). Note that there is a change in 1988 from taking ratios of averages to taking average ratios (see note 2 to table 517 at the above link). 
Figure 2.1.3 Local authority housing stock sold through the right to buy scheme in England, 1980 - 2009

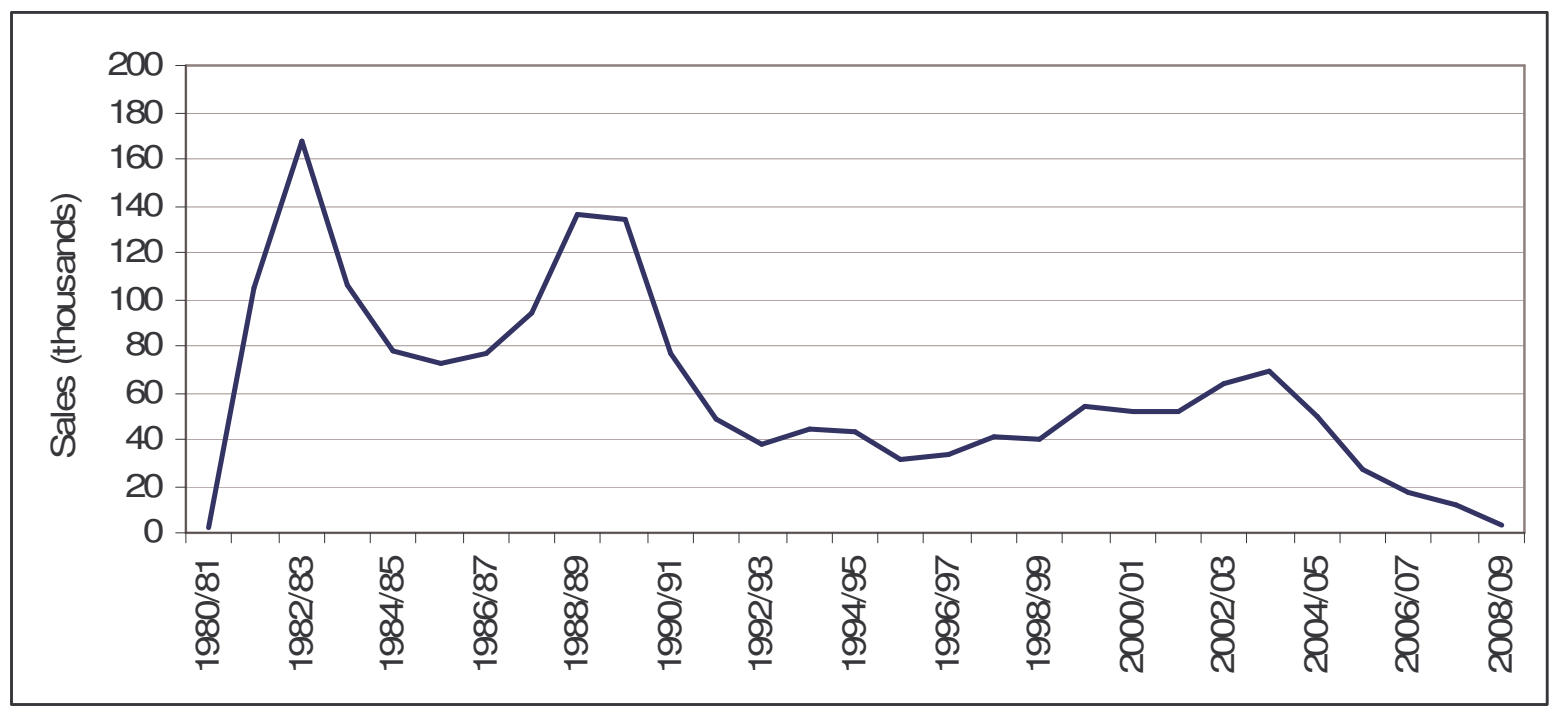

Notes: This chart uses data and reproduces a figure that are published by the Department for Communities and Local Government: see chart 671 via

http://www.communities.gov.uk/housing/housingresearch/housingstatistics/housingstatisticsby/socialhousingsales/liveta bles/ 
Figure 3.1.1: Proportion of individuals aged thirty who are owner-occupiers, and log real (mixadjusted) house price, 1971-2007, England.

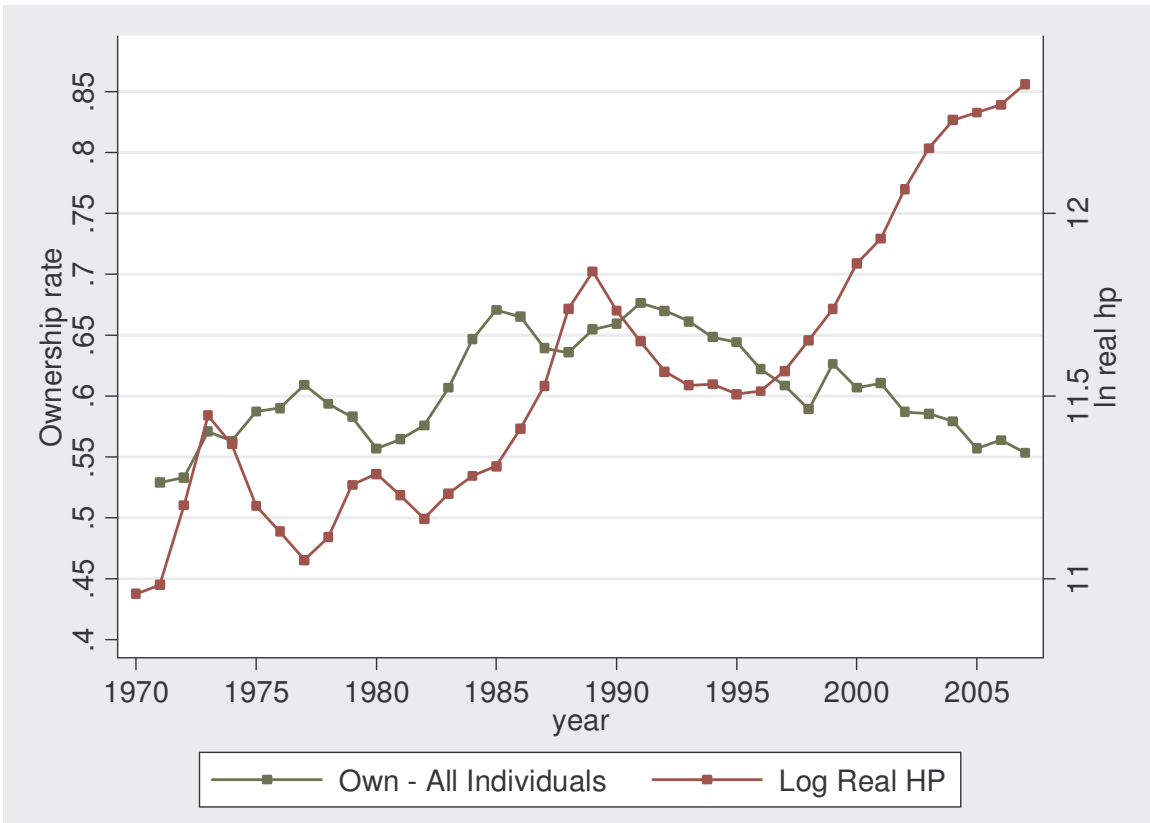


Figure 3.1.2: Proportion of men and women aged thirty who are owner-occupiers, and log real (mix-adjusted) house price, 1971-2007, England

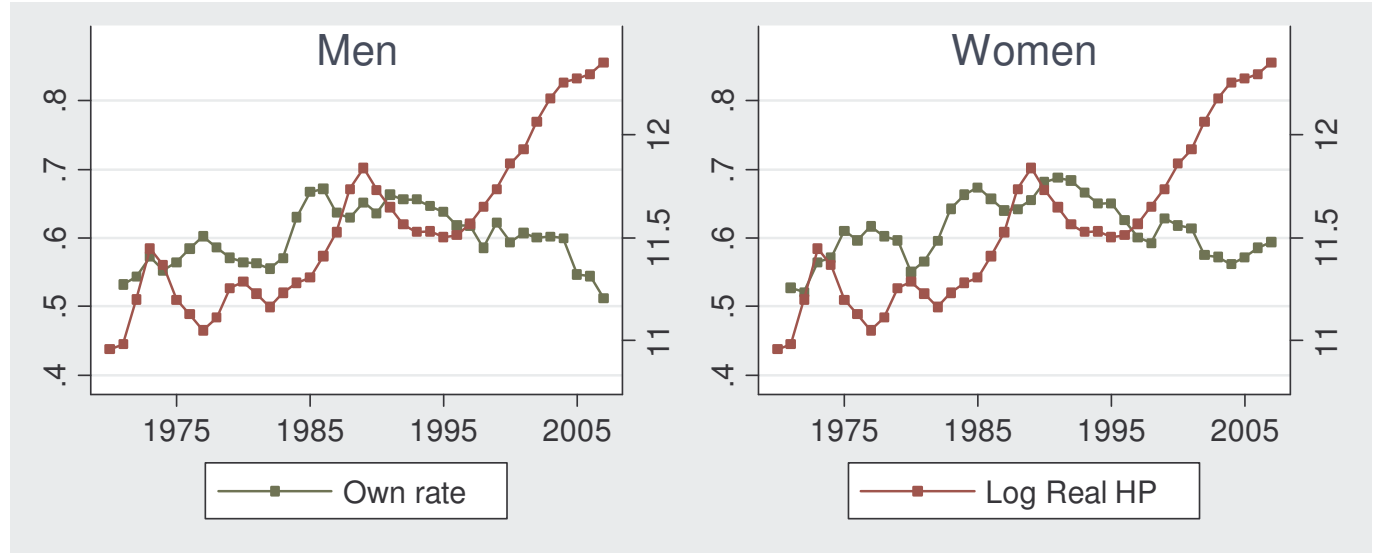

Figure 3.1.3: Proportion of men and women aged thirty who are owner-occupiers, and log real (mix-adjusted) house price, 1971-2007, by region.

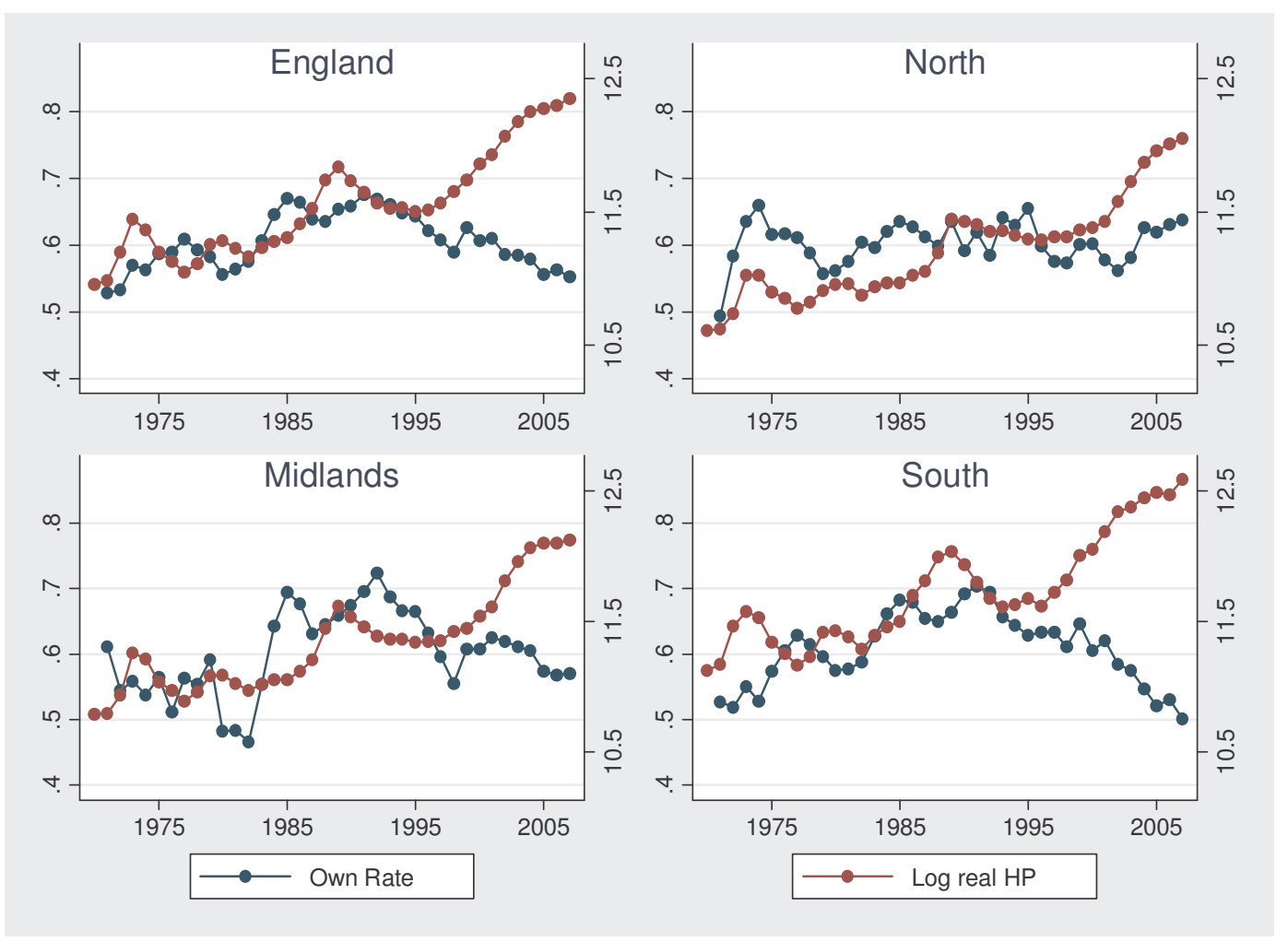


Figure 3.1.4: Proportion of individuals aged thirty and living in couples who are owneroccupiers, and log real (mix-adjusted) house price, 1971-2007, England

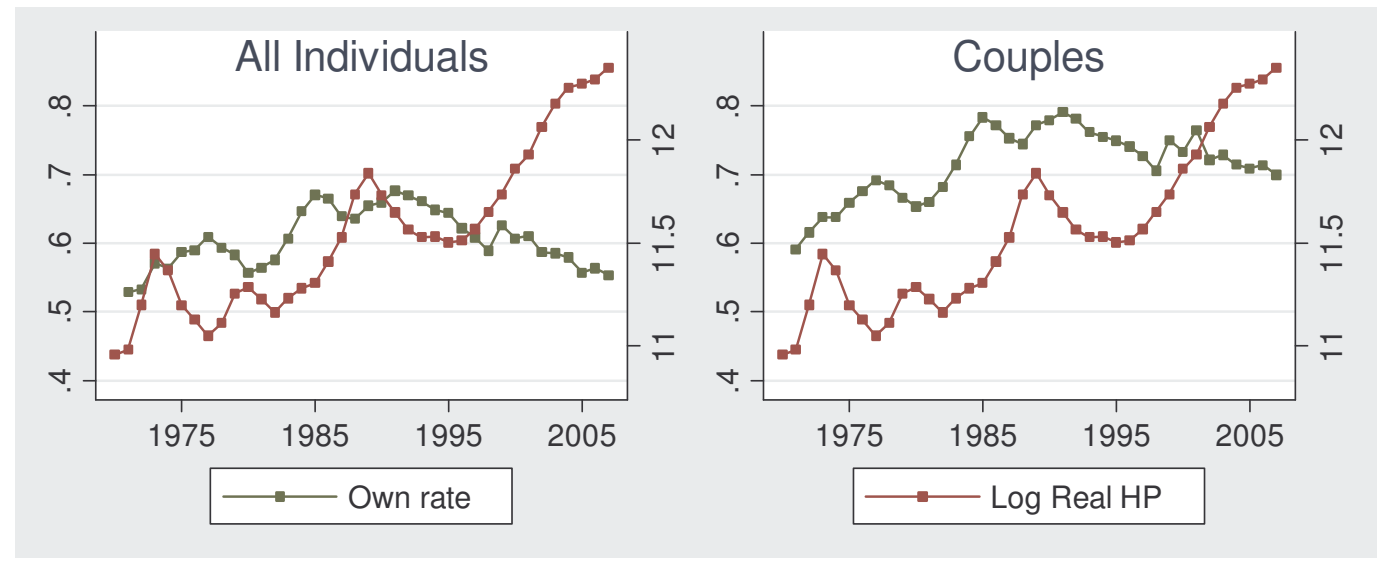

Figure 3.1.5: Proportion of individuals aged thirty who are owner-occupiers, with the same by couple status, and the proportion of thirty-year olds who are in couples, 1971-2007, England.

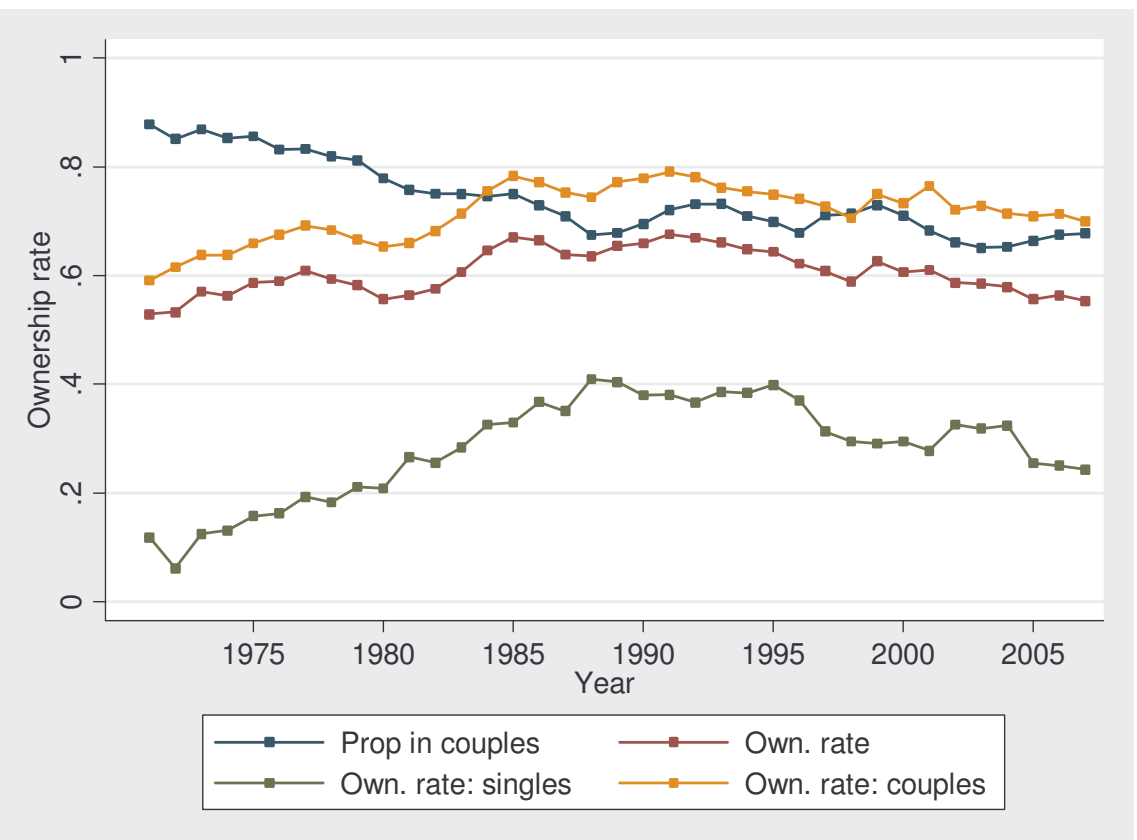


Figure 4.1.1: Ownership rates at different ages by year: all individuals, England

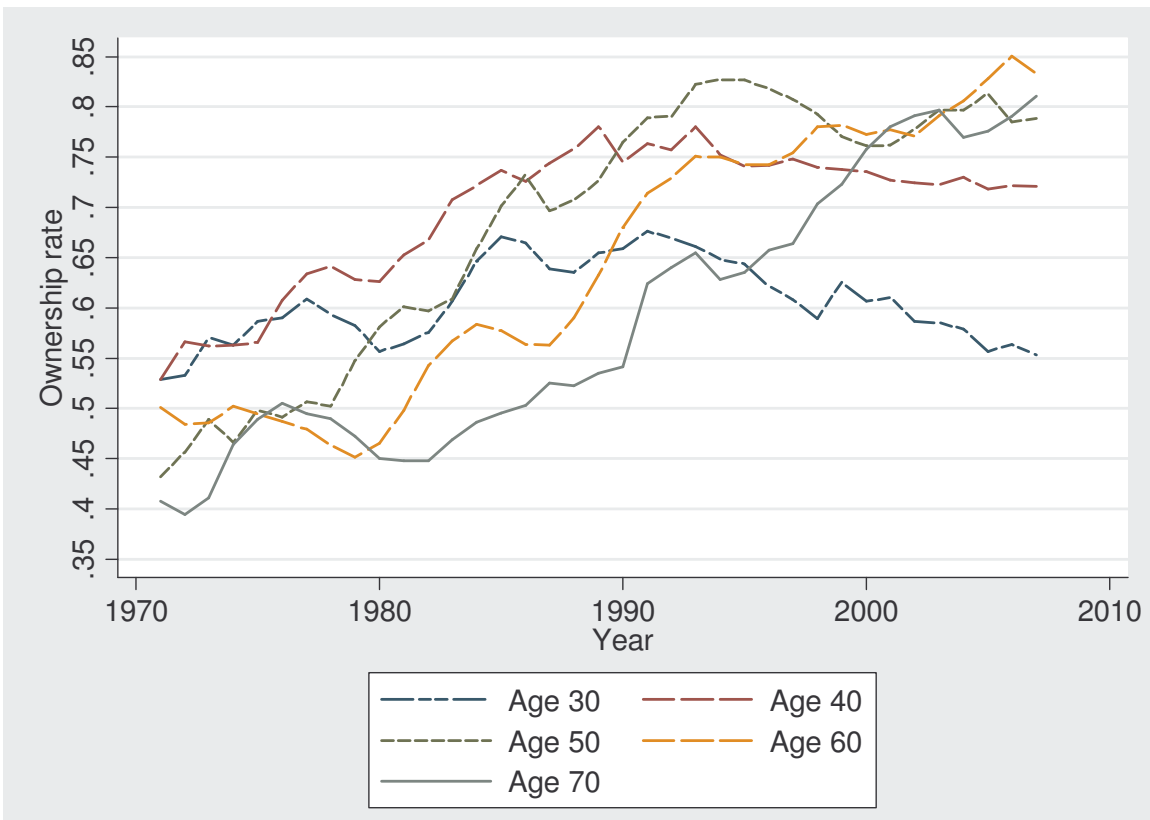


Figure 4.1.2: Catch-up by forty?

Ownership change (rate at forty - rate at thirty), against ownership at thirty,

England and regions

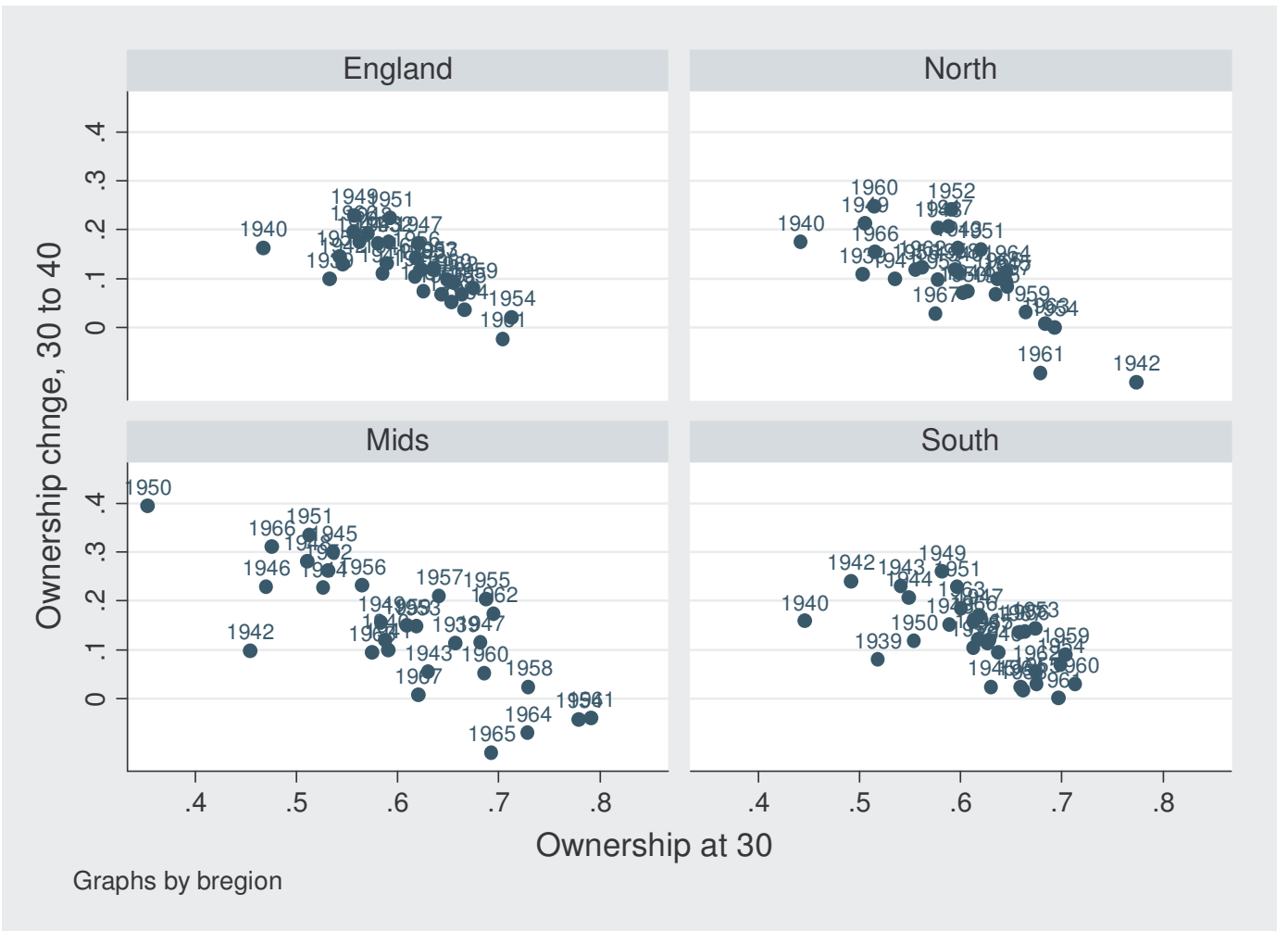


Figure 4.1.3: Catch-up by fifty?

Ownership change (rate at fifty - rate at thirty), against ownership at thirty,

England and regions

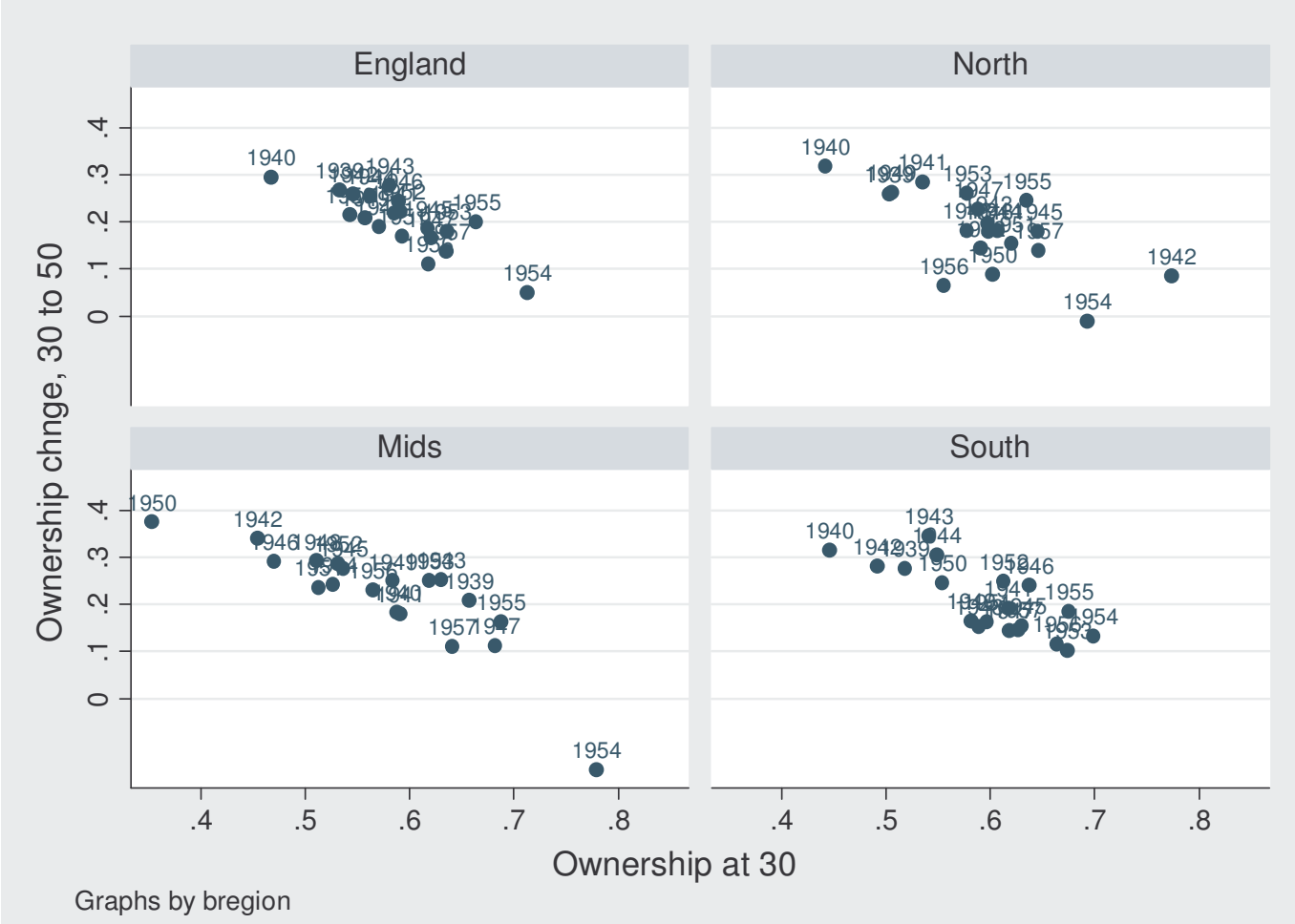


Figure A.1: Population sizes by broad region for (10year) cohorts

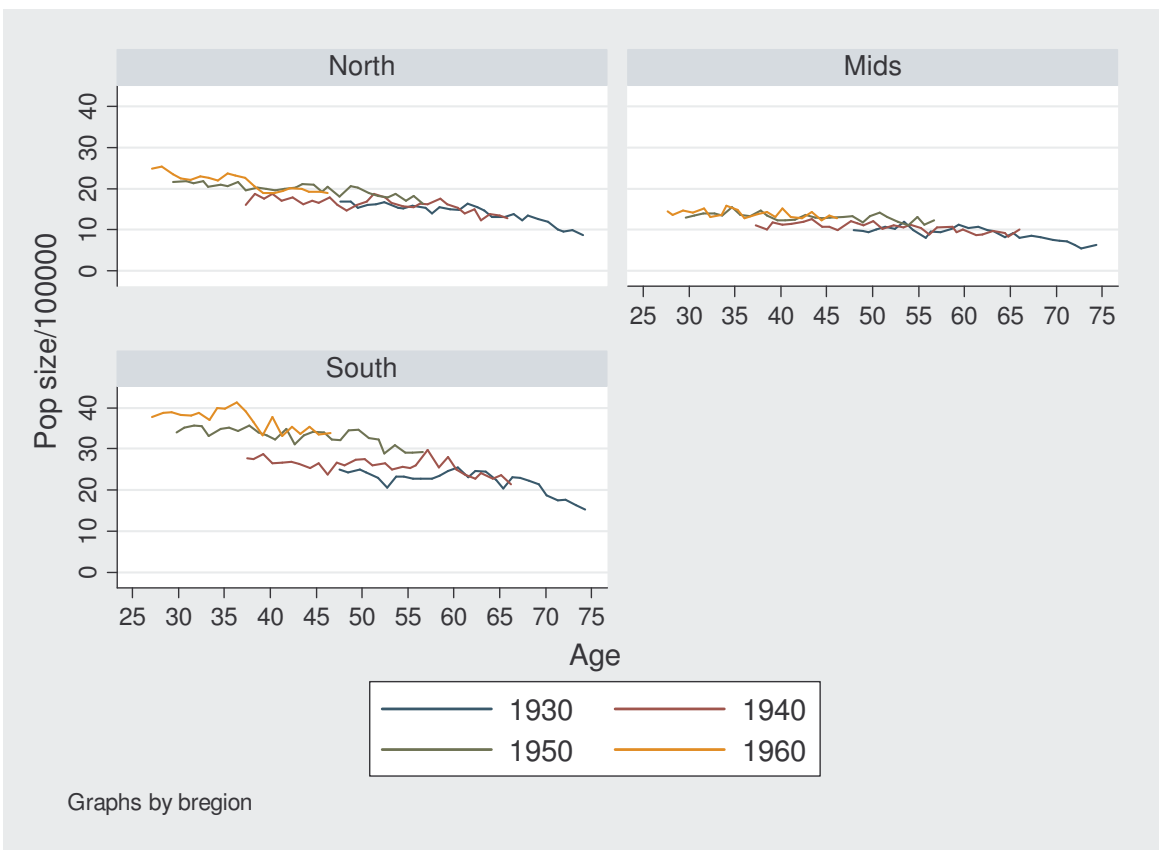

Figure A.2: Proportion who left full-time education at or after age 18

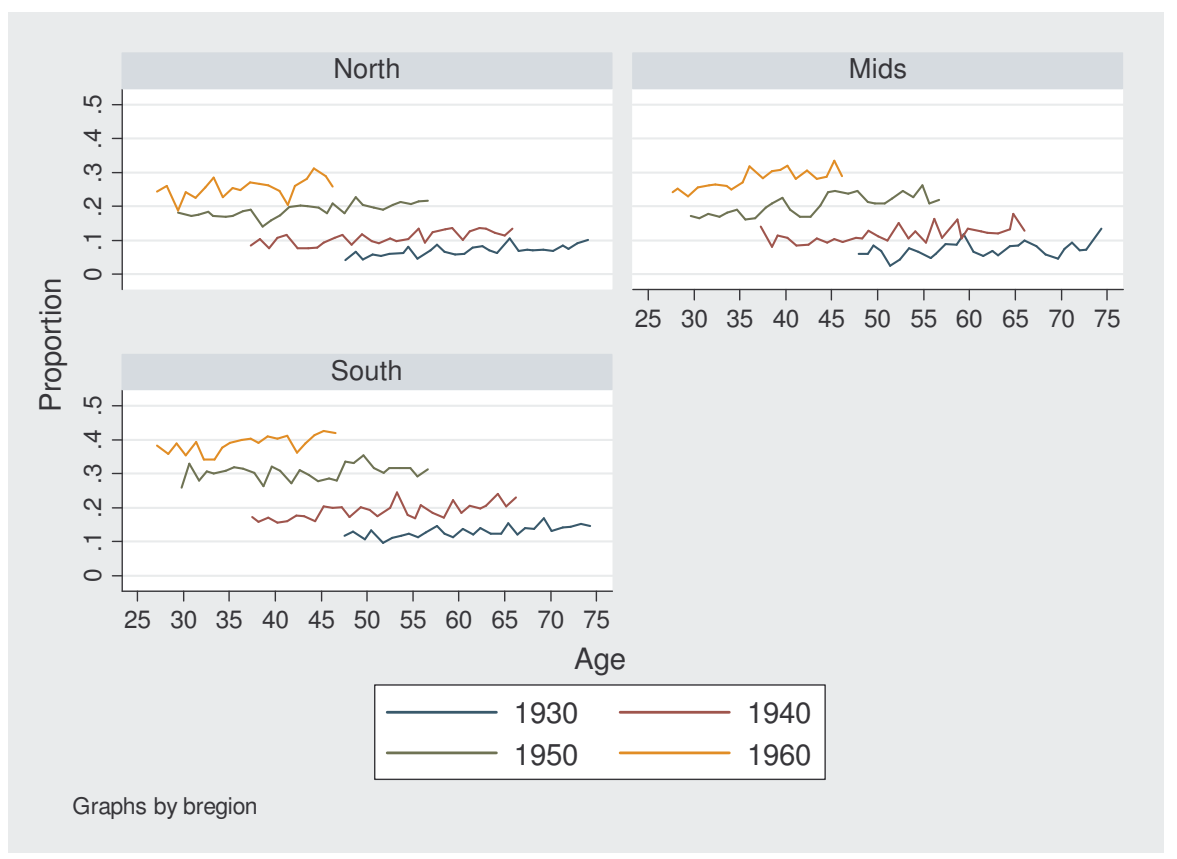


Table 3.1.1: Probit Regression for Ownership at Thirty, Pooled Data for England Dependent Variable: Ownership at thirty

\begin{tabular}{|c|c|c|c|c|}
\hline Regressor & Coeff & & Standard error & Marginal effect \\
\hline Time trend & -0.0047 & & 0.0090 & -0.0018 \\
\hline Log real house price & -0.4932 & *** & 0.1049 & -0.1899 \\
\hline RTB sales this year & 0.3335 & $* * *$ & 0.0508 & 0.1284 \\
\hline Cumulative RTB sales & 0.0154 & & 0.0152 & 0.0059 \\
\hline Log family income & 0.9243 & **** & 0.0588 & 0.3559 \\
\hline Female $(0 / 1)$ & 0.1038 & $* * *$ & 0.0346 & 0.0400 \\
\hline Couple $(0 / 1)$ & 0.6615 & **** & 0.0559 & 0.2574 \\
\hline Number of kids & -0.1311 & *** & 0.0181 & -0.0505 \\
\hline Post-compuls Educ (0/1) & - & & & \\
\hline \multicolumn{5}{|c|}{ Eight region dummies and a constant are also included } \\
\hline \multicolumn{5}{|c|}{5687 observations, pseudo r-squared 0.2122} \\
\hline \multicolumn{5}{|c|}{ Marginal effects calculated at means of independent variables } \\
\hline \multicolumn{5}{|c|}{ Standard errors clustered at the region-year level } \\
\hline
\end{tabular}


Table 3.1.2: Probit Regression for Ownership at Thirty, Pooled Data for England Dependent Variable: Ownership at thirty

\begin{tabular}{|l|ll|l|l|}
\hline Regressor & Coeff & Standard error & Marginal effect \\
\hline Time trend & -0.0775 & $* * *$ & 0.0163 & -0.0296 \\
Log real house price & -0.2985 & $* *$ & 0.1323 & -0.1138 \\
RTB sales this year & 0.2757 & $* * *$ & 0.0556 & 0.1051 \\
Cumulative RTB sales & 0.1089 & $* * *$ & 0.0216 & 0.0415 \\
Log family income & 0.9193 & $* * *$ & 0.0629 & 0.3506 \\
Female (0/1) & 0.0720 & $*$ & 0.0395 & 0.0275 \\
Couple (0/1) & 0.6216 & $* * *$ & 0.0603 & 0.2405 \\
Number of kids & -0.1057 & $* * *$ & 0.0213 & -0.0403 \\
Post-compuls Educ (0/1) & 0.2237 & $* * *$ & 0.0457 & 0.0853 \\
\multicolumn{4}{|l}{} \\
Eight region dummies and a constant are also included & \\
\hline 4623 observations, pseudo r-squared 0.2292 \\
Marginal effects calculated at means of independent variables \\
Standard errors clustered at the region-year level \\
\hline
\end{tabular}


Table 4.1.1 Descriptive statistics for ownership rate at thirty and forty, among cohorts observed at both ages (for England)

\begin{tabular}{|c|c|c|c|c|c|}
\hline & Mean & Variance & Median & $\begin{array}{c}\text { Minimum } \\
\text { observed }\end{array}$ & $\begin{array}{c}\text { Maximum } \\
\text { observed }\end{array}$ \\
\hline Age 40 & 0.729 & 0.0019 & 0.737 & 0.631 & 0.817 \\
\hline Age 30 & 0.609 & 0.0030 & 0.618 & 0.468 & 0.713 \\
\hline
\end{tabular}

Note: Based on 29 observations at each age, (1979-2007 for age 40, 1969-1987 for age 30).

Table 4.1.2 Descriptive statistics for ownership rate at thirty and fifty, among cohorts observed at both ages (for England)

\begin{tabular}{|l|c|c|c|c|c|}
\hline & Mean & Variance & Median & $\begin{array}{c}\text { Minimum } \\
\text { observed }\end{array}$ & $\begin{array}{c}\text { Maximum } \\
\text { observed }\end{array}$ \\
\hline Age 50 & 0.793 & 0.0013 & 0.801 & 0.729 & 0.863 \\
\hline Age 30 & 0.591 & 0.0029 & 0.589 & 0.468 & 0.713 \\
\hline
\end{tabular}

Note: Based on 19 observations at each age, (1989-2007 for age 50, 1969-1997 for age 30). 
Table 4.2.1: Catch-up Regression Estimates

Dependent variable: change in ownership rate, age forty minus age thirty, England

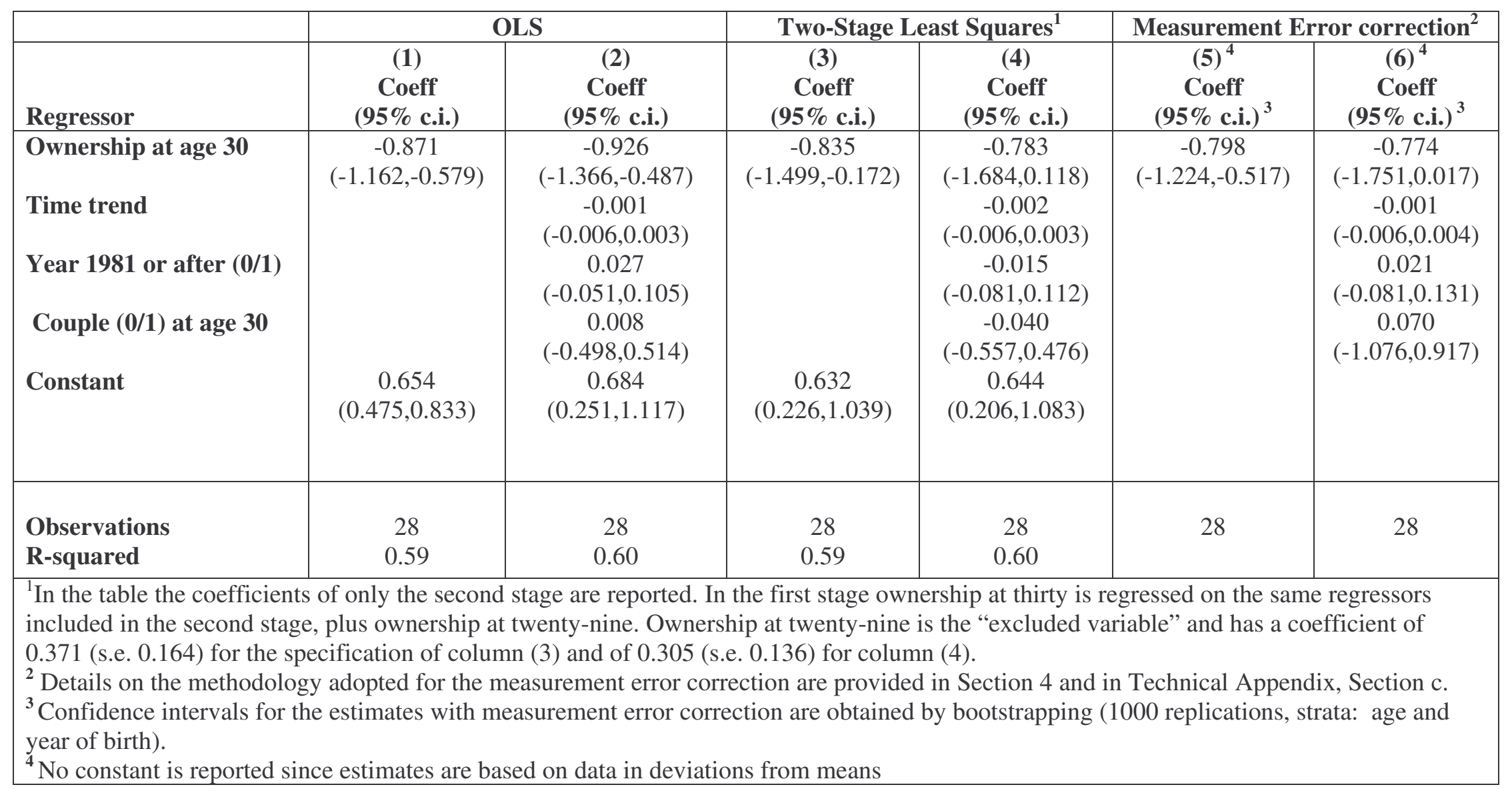


Year of Birth

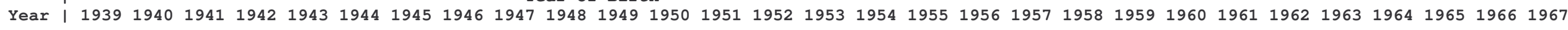
1969 | .533

$1970 \quad .595 .468$

\begin{tabular}{l|lll}
1971 & $.512 .557 \quad .586$
\end{tabular}

\begin{tabular}{l|llll}
1972 & .578 & .589 & $.602 \quad .545$
\end{tabular}

\begin{tabular}{l|lllll}
1973 & .559 & .598 & .574 & .58 & .581
\end{tabular}

\begin{tabular}{l|llllll}
1974 & .601 & .606 & .561 & .664 & .6 & .563
\end{tabular}

\begin{tabular}{l|lllllll}
1975 & .635 & .613 & .653 & .599 & .574 & .601 & .617
\end{tabular}

\begin{tabular}{l|l|l|l|l|l|l|l|l|l}
1976 & 629 & 603 & 632 & 66 & 642 & 642 & 585 & 589
\end{tabular}

\begin{tabular}{l|lllllllll}
1977 & .628 & .644 & .546 & .613 & .573 & .69 & .636 & .639
\end{tabular}

$1978 \quad .638 .621 .668 .642-633 \quad .624 .652 .679-62 \quad .620 .571$

$1979+.632 .621 .668 .642 .633 .624 .652 .679 .622 .571 .0738 .654 .633 .727 .588 .644 .557$

\begin{tabular}{l|llllllllllll}
1980 & .683 & .631 & .701 & .635 & .69 & .706 & .681 & .648 & .686 & .64 & .657 & .643 \\
1988 & .553 & .636 & .696 & .667 & .66 & .659 & .693 & .651 & .689 & .639 & .655 & .62
\end{tabular}

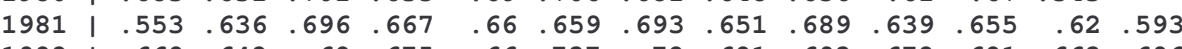

\begin{tabular}{l|lllllllllllllll}
1982 & .668 & .642 & .68 & .675 & .66 & .737 & .72 & .681 & .693 & .672 & .681 & .663 & .696 & .591
\end{tabular}

\begin{tabular}{l|lllllllllllllll}
1983 & .687 & .662 & .738 & .718 & .753 & .79 & .721 & .772 & .778 & .735 & .663 & .673 & .739 & .641 & .635
\end{tabular}

\begin{tabular}{l|lllllllllllllllll}
1984 & .774 & .719 & .739 & .717 & .684 & .737 & .719 & .698 & .759 & .693 & .731 & .71 & .686 & .61 & .599 & .713
\end{tabular}

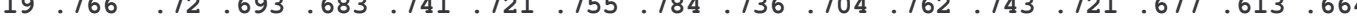

\begin{tabular}{l|llllllllllllllllllll}
1986 & .73 & .746 & .75 & .797 & .79 & .783 & .771 & .72 & .684 & .717 & .746 & .728 & .761 & .754 & .702 & .691 & .669 & .618
\end{tabular}

\begin{tabular}{l|llllllllllllllllllll} 
& .786 & .711 & .766 & .767 & .78 & .758 & .817 & .769 & .793 & .746 & .739 & .707 & .742 & .724 & .737 & .64 & .683 & .682 & .635
\end{tabular}

\begin{tabular}{l|lllllllllllllllllllll}
1988 & .736 & .709 & .794 & .737 & .756 & .81 & .771 & .757 & .78 & .762 & .801 & .717 & .753 & .707 & .73 & .636 & .74 & .702 & .605 & .653 & \\
\hline
\end{tabular}

\begin{tabular}{l|lllllllllllllllllllll}
1989 & .801 & .697 & .766 & .76 & .774 & .802 & .77 & .792 & .778 & .758 & .786 & .789 & .722 & .78 & .748 & .724 & .747 & .703 & .7656 & .699 & .675
\end{tabular}

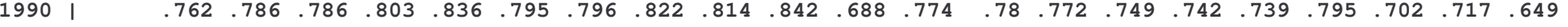

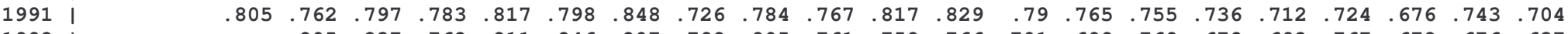

1992

$\begin{array}{llllllllllllllllllllll}805 & .837 & .762 & .811 & .846 & .807 & .798 & .805 & .761 & .758 & .766 & .701 & .699 & .769 & .679 & .692 & .767 & .678 & .676 & .637 & .656\end{array}$

1993

$\begin{array}{llllllllllllllllllllllll}858 & .796 & .853 & .824 & .843 & .769 & 752 & .794 & .777 & .75 & .757 & .686 & .767 & .721 & .757 & .674 & .756 & .684 & .667 & .671 & .623\end{array}$

1994

\begin{tabular}{lllllllllllllllllllllll}
.818 & .851 & .833 & 825 & 803 & 814 & .83 & .737 & .826 & .747 & .734 & .759 & .817 & .708 & .696 & .699 & .75 & .682 & .684 & .633 & .666 & & \\
\hline
\end{tabular}

1995

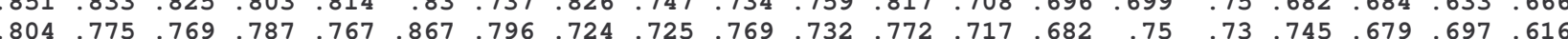

1996

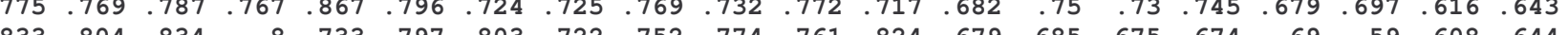

1997 |

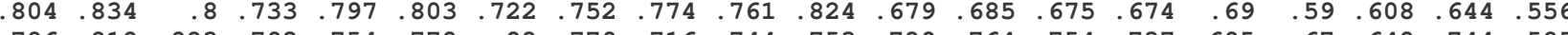

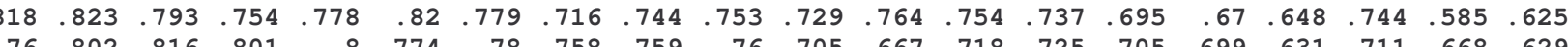

$\begin{array}{llllllllllllllllllll}.802 & .816 & .801 & .8 & .774 & .78 & .758 & .759 & .76 & .705 & .667 & .718 & .725 & .705 & .699 & .631 & .711 & .668 & .629\end{array}$ $\begin{array}{llllllllllllllllllll} & .809 & .78 & .8 & .825 & .808 & .8 & .767 & .756 & .694 & .755 & .772 & .752 & .723 & .768 & .683 & .649 & .675 & .668\end{array}$

(2000

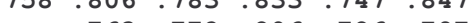

$\begin{array}{llllllllllllllllll}763 & .772 & .806 & .786 & .797 & .823 & .78 & .779 & .717 & .694 & .681 & .764 & .714 & .717 & .669 & .705 & .697\end{array}$

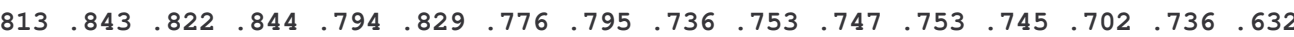

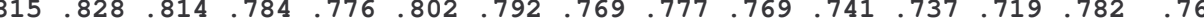

2001

2002

$\begin{array}{llllllllllllllll}.763 & .787 & .771 & .829 & .794 & .743 & .765 & .716 & .759 & .73 & .701 & .686 & .71 & .69\end{array}$

$\begin{array}{lllllllllllll}863 & .75 & .79 & .813 & .791 & .766 & .728 & .737 & .717 & .749 & .712 & .697 & .763\end{array}$

2004 $\begin{array}{llllllllllll}.729 & .797 & .815 & .794 & .779 & .749 & .755 & .775 & .782 & .75 & .752 & .731\end{array}$

2006 $\begin{array}{lllllllllll}772 & .793 & .736 & .758 & .781 & .766 & .72 & .716 & .737 & .725\end{array}$ 


\section{Table A.2 Cell Sizes}

| 193919401941194219431944194519461947 Year of Birth

year | 19391940194119421943194419451946194719481949195019511952195319541955195619571958195919601961196219631964196519661967

\begin{tabular}{|c|c|c|c|c|c|c|c|c|c|c|c|c|c|c|c|c|c|c|c|c|c|c|c|c|c|c|c|c|c|c|}
\hline 1969 & 1 & 222 & & & & & & & & & & & & & & & & & & & & & & & & & & & & \\
\hline 1970 & i & 183 & 180 & & & & & & & & & & & & & & & & & & & & & & & & & & & \\
\hline 1971 & i & 239 & 222 & 222 & & & & & & & & & & & & & & & & & & & & & & & & & & \\
\hline 1972 & i & 187 & 214 & 215 & 221 & & & & & & & & & & & & & & & & & & & & & & & & & \\
\hline 1973 & i & 204 & 189 & 212 & 202 & 245 & & & & & & & & & & & & & & & & & & & & & & & & \\
\hline 1974 & i & 191 & 187 & 192 & 214 & 229 & 210 & & & & & & & & & & & & & & & & & & & & & & & \\
\hline 1975 & $i$ & 208 & 208 & 196 & 206 & 247 & 232 & 247 & & & & & & & & & & & & & & & & & & & & & & \\
\hline 1976 & i & 204 & 201 & 185 & 219 & 188 & 233 & 241 & 235 & & & & & & & & & & & & & & & & & & & & & \\
\hline 1977 & i & 199 & 210 & 184 & 210 & 204 & 204 & 244 & 272 & 325 & & & & & & & & & & & & & & & & & & & & \\
\hline 1978 & i & 178 & 184 & 184 & 193 & 228 & 197 & 202 & 203 & 301 & 282 & & & & & & & & & & & & & & & & & & & \\
\hline 1979 & i & 194 & 162 & 185 & 188 & 204 & 224 & 217 & 216 & 251 & 266 & 256 & & & & & & & & & & & & & & & & & & \\
\hline 1980 & i & 171 & 171 & 170 & 217 & 219 & 250 & 239 & 250 & 262 & 269 & 207 & 234 & & & & & & & & & & & & & & & & & \\
\hline 1981 & i & 209 & 192 & 184 & 219 & 221 & 248 & 274 & 247 & 322 & 302 & 273 & 273 & 247 & & & & & & & & & & & & & & & & \\
\hline 1982 & i & 191 & 212 & 190 & 199 & 215 & 218 & 267 & 261 & 334 & 280 & 252 & 252 & 255 & 220 & & & & & & & & & & & & & & & \\
\hline 1983 & i & 176 & 186 & 200 & 168 & 206 & 212 & 228 & 219 & 309 & 262 & 261 & 234 & 229 & 223 & 227 & & & & & & & & & & & & & & \\
\hline 1984 & $i$ & 174 & 177 & 189 & 190 & 204 & 218 & 198 & 175 & 230 & 230 & 227 & 240 & 239 & 243 & 199 & 246 & & & & & & & & & & & & & \\
\hline 1985 & 1 & 164 & 166 & 158 & 190 & 191 & 165 & 196 & 215 & 275 & 262 & 259 & 235 & 238 & 217 & 215 & 215 & 228 & & & & & & & & & & & & \\
\hline 1986 & i & 151 & 155 & 166 & 190 & 191 & 218 & 182 & 235 & 234 & 223 & 219 & 223 & 228 & 211 & 226 & 229 & 236 & 234 & & & & & & & & & & & \\
\hline 1987 & i & 157 & 167 & 141 & 164 & 199 & 202 & 199 & 208 & 247 & 267 & 234 & 241 & 236 & 219 & 254 & 210 & 235 & 229 & 259 & & & & & & & & & & \\
\hline 1988 & i & 169 & 170 & 150 & 183 & 167 & 188 & 226 & 240 & 265 & 256 & 227 & 218 & 217 & 197 & 249 & 242 & 202 & 216 & 212 & 211 & & & & & & & & & \\
\hline 1989 & i & 162 & 161 & 157 & 163 & 182 & 197 & 220 & 222 & 269 & 237 & 250 & 205 & 230 & 186 & 216 & 244 & 204 & 212 & 228 & 216 & 230 & & & & & & & & \\
\hline 1990 & i & & 136 & 135 & 144 & 172 & 204 & 176 & 179 & 230 & 226 & 202 & 211 & 188 & 199 & 186 & 193 & 228 & 222 & 218 & 202 & 246 & 223 & & & & & & & \\
\hline 1991 & i & & & 134 & 155 & 181 & 178 & 200 & 208 & 202 & 179 & 200 & 178 & 202 & 204 & 211 & 199 & 198 & 199 & 234 & 234 & 209 & 208 & 196 & & & & & & \\
\hline 1992 & i & & & & 155 & 211 & 179 & 203 & 200 & 273 & 229 & 195 & 218 & 189 & 202 & 220 & 214 & 211 & 220 & 246 & 235 & 248 & 238 & 267 & 243 & & & & & \\
\hline 1993 & i & & & & & 167 & 161 & 176 & 176 & 234 & 222 & 190 & 175 & 192 & 163 & 198 & 194 & 193 & 212 & 212 & 216 & 240 & 196 & 245 & 216 & 265 & & & & \\
\hline 1994 & i & & & & & & 170 & 149 & 164 & 229 & 220 & 203 & 182 & 192 & 182 & 178 & 197 & 195 & 198 & 211 & 227 & 216 & 207 & 198 & 225 & 222 & 228 & & & \\
\hline 1995 & i & & & & & & & 144 & 188 & 219 & 213 & 181 & 182 & 188 & 165 & 198 & 202 & 178 & 187 & 205 & 210 & 209 & 212 & 229 & 225 & 236 & 255 & 235 & & \\
\hline 1996 & i & & & & & & & & 172 & 196 & 193 & 189 & 149 & 160 & 173 & 153 & 190 & 180 & 187 & 184 & 202 & 235 & 199 & 213 & 251 & 238 & 241 & 241 & 224 & \\
\hline 1997 & i & & & & & & & & & 204 & 168 & 160 & 180 & 162 & 170 & 152 & 181 & 180 & 176 & 185 & 178 & 228 & 211 & 234 & 229 & 222 & 202 & 241 & 211 & 194 \\
\hline 1998 & i & & & & & & & & & & 159 & 170 & 145 & 169 & 153 & 146 & 152 & 152 & 199 & 175 & 194 & 172 & 189 & 197 & 186 & 209 & 212 & 212 & 199 & 194 \\
\hline 1999 & i & & & & & & & & & & & 165 & 158 & 178 & 131 & 169 & 180 & 166 & 166 & 177 & 179 & 197 & 185 & 177 & 202 & 204 & 226 & 207 & 227 & 246 \\
\hline 2000 & i & & & & & & & & & & & & 179 & 160 & 152 & 163 & 180 & 165 & 152 & 152 & 155 & 151 & 164 & 195 & 163 & 189 & 181 & 218 & 217 & 203 \\
\hline 2001 & i & & & & & & & & & & & & & 174 & 164 & 178 & 180 & 174 & 206 & 185 & 203 & 196 & 210 & 249 & 204 & 237 & 237 & 242 & 244 & 205 \\
\hline 2002 & i & & & & & & & & & & & & & & 177 & 181 & 157 & 155 & 176 & 170 & 191 & 160 & 192 & 221 & 197 & 210 & 216 & 210 & 214 & 228 \\
\hline 2003 & i & & & & & & & & & & & & & & & 156 & 174 & 159 & 172 & 200 & 169 & 188 & 189 & 193 & 206 & 227 & 246 & 223 & 207 & 190 \\
\hline 2004 & i & & & & & & & & & & & & & & & & 163 & 153 & 177 & 175 & 186 & 186 & 190 & 195 & 216 & 213 & 224 & 195 & 191 & 190 \\
\hline 2005 & i & & & & & & & & & & & & & & & & & 141 & 155 & 166 & 180 & 183 & 191 & 188 & 178 & 212 & 198 & 217 & 212 & 217 \\
\hline 2006 & i & & & & & & & & & & & & & & & & & & 133 & 169 & 178 & 189 & 162 & 189 & 200 & 210 & 186 & 192 & 202 & 169 \\
\hline 2007 & I & & & & & & & & & & & & & & & & & & & 165 & 149 & 168 & 158 & 163 & 190 & 169 & 161 & 164 & 175 & 153 \\
\hline
\end{tabular}




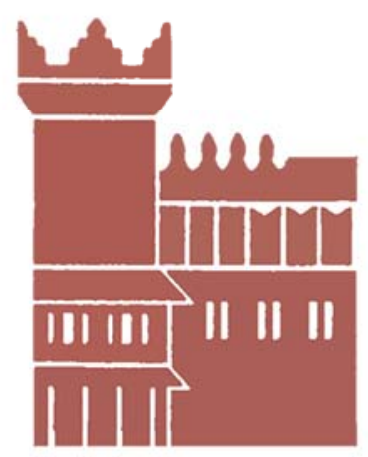

Alma Mater Studiorum - Università di Bologna DEPARTMENT OF ECONOMICS

Strada Maggiore 45

40125 Bologna - Italy

Tel. +39051 2092604

Fax +390512092664

http://www.dse.unibo.it 